\title{
Sustained CTL activation by murine pulmonary epithelial cells promotes the development of COPD-like disease
}

\author{
Michael T. Borchers, ${ }^{1,2}$ Scott C. Wesselkamper, ${ }^{1}$ Victor Curull, ${ }^{3,4,5}$ Alba Ramirez-Sarmiento, ${ }^{3,4}$ \\ Albert Sánchez-Font, ${ }^{3,4}$ Judith Garcia-Aymerich, ${ }^{6}$ Carlos Coronell, ${ }^{3}$ Josep Lloreta, 7,8 \\ Alvar G. Agusti, 9,10 Joaquim Gea,4,7,9 John A. Howington, ${ }^{11}$ Michael F. Reed, ${ }^{11}$ Sandra L. Starnes, ${ }^{11}$ \\ Nathaniel L. Harris, ${ }^{1}$ Mark Vitucci, ${ }^{1}$ Bryan L. Eppert, ${ }^{1}$ Gregory T. Motz, ${ }^{1}$ Kevin Fogel, ${ }^{2}$ \\ Dennis W. McGraw, ${ }^{2}$ Jay W. Tichelaar, ${ }^{12}$ and Mauricio Orozco-Levi 3 ,4,7,9
}

\begin{abstract}
1Department of Environmental Health, Division of Environmental Genetics and Molecular Toxicology, and 2Department of Internal Medicine, Division of Pulmonary and Critical Care, University of Cincinnati College of Medicine, Cincinnati, Ohio, USA. ${ }^{3}$ Group of Research on Injury, Immune Response, and Lung Function, Institut Municipal d'Investigació Mèdica (IMIM), Barcelona, Spain. ${ }^{4}$ Servei de Pneumologia, Hospital del Mar, Barcelona, Spain. ${ }^{5}$ Universitat Autònoma de Barcelona, Barcelona, Spain. ${ }^{6}$ Centre for Research in Environmental Epidemiology (CREAL), IMIM, Barcelona, Spain. ${ }^{7} \mathrm{CEXS}$, Universitat Pompeu Fabra, Barcelona, Spain. ${ }^{8}$ Servei d'Anatomia Patològica, Hospital del Mar, Barcelona, Spain. ${ }^{9} \mathrm{CIBER}$ de Enfermedades Respiratorias, Instituto de Salud Carlos III, Ministerio de Ciencia y Tecnología, Madrid, Spain. ${ }^{10}$ Hospital Universitario Son Dureta y Fundación Caubet-Cimera Illes Balears, Majorca, Spain. ${ }^{11}$ Department of Surgery, Division of Thoracic Surgery, University of Cincinnati College of Medicine, Cincinnati, Ohio, USA. ${ }^{12}$ Department of Surgery, Washington University, St. Louis, Missouri, USA.
\end{abstract}

\begin{abstract}
Chronic obstructive pulmonary disease (COPD) is a lethal progressive lung disease culminating in permanent airway obstruction and alveolar enlargement. Previous studies suggest CTL involvement in COPD progression; however, their precise role remains unknown. Here, we investigated whether the CTL activation receptor NK cell group 2D (NKG2D) contributes to the development of COPD. Using primary murine lung epithelium isolated from mice chronically exposed to cigarette smoke and cultured epithelial cells exposed to cigarette smoke extract in vitro, we demonstrated induced expression of the NKG2D ligand retinoic acid early transcript 1 (RAET1) as well as NKG2D-mediated cytotoxicity. Furthermore, a genetic model of inducible RAET1 expression on mouse pulmonary epithelial cells yielded a severe emphysematous phenotype characterized by epithelial apoptosis and increased CTL activation, which was reversed by blocking NKG2D activation. We also assessed whether NKG2D ligand expression corresponded with pulmonary disease in human patients by staining airway and peripheral lung tissues from never smokers, smokers with normal lung function, and current and former smokers with COPD. NKG2D ligand expression was independent of NKG2D receptor expression in COPD patients, demonstrating that ligand expression is the limiting factor in CTL activation. These results demonstrate that aberrant, persistent NKG2D ligand expression in the pulmonary epithelium contributes to the development of COPD pathologies.
\end{abstract}

\section{Introduction}

Chronic obstructive pulmonary disease (COPD) is a progressive disease of the lung characterized by inflammation, largely irreversible airflow obstruction, and permanent alveolar enlargement (1). COPD afflicts more than 12 million adults and is the fourth leading cause of death in the United States. Further increases in prevalence of and mortality caused by COPD are predicted in the coming decades $(1,2)$. Currently, questions remain about the pathophysiological mechanisms controlling COPD, and, despite numerous clinical trials, therapy is limited mainly to supportive measures.

A prominent mechanism of airflow obstruction in COPD is emphysema. Emphysema is characterized by the permanent enlargement of airspaces accompanied by the loss of elastic recoil of the lung. The pathogenesis of the destruction of the alveolar unit in emphysema is complex and incompletely understood,

Conflict of interest: The authors have declared that no conflict of interest exists. Nonstandard abbreviations used: BAL, bronchoalveolar lavage; Casp3, caspase 3; COPD, chronic obstructive pulmonary disease; CSE, cigarette smoke extract; DOX, doxycycline; MIC, MHC class I chain-related; NKG2D, NK cell group 2D; RAET1, retinoic acid early transcript $1 ; \mathrm{TL}_{\mathrm{CO}}$, lung transfer capacity for $\mathrm{CO}$.

Citation for this article: J. Clin. Invest. 119:636-649 (2009). doi:10.1172/JCI34462. but is thought to involve chronic inflammation, leukocyte activation, oxidative stress, and increased elastolytic potential in the lung (3). Increased numbers of macrophages, neutrophils, and lymphocytes in the airways, parenchyma, and vasculature characterize the inflammation. Macrophages and neutrophils are well studied and seemingly contribute to tissue destruction through the liberation of extracellular matrix-degrading proteinases (3). A potential role for lymphocytes in COPD pathology is becoming increasingly appreciated (4-6). However, mechanistic data in support of causal role for lymphocytes in the development or progression of COPD are limited.

Cells undergoing physical or chemical stress are removed in order to control inflammation and promote repair. Multiple mechanisms for the detection and elimination of cells undergoing stress have been described previously (7). One system that may provide a mechanistic link between epithelial cell stress caused by cigarette smoking and immune cell activation in the lung involves NK cell group 2D (NKG2D; also known as KLRK1) receptor activation. The NKG2D receptor is expressed on circulating and tissue lymphocytes and directly recognizes stressed cells through ligands expressed on the cell surface (8). NKG2D receptors are expressed almost exclusively on CTLs (i.e., CD8 ${ }^{+}$ 

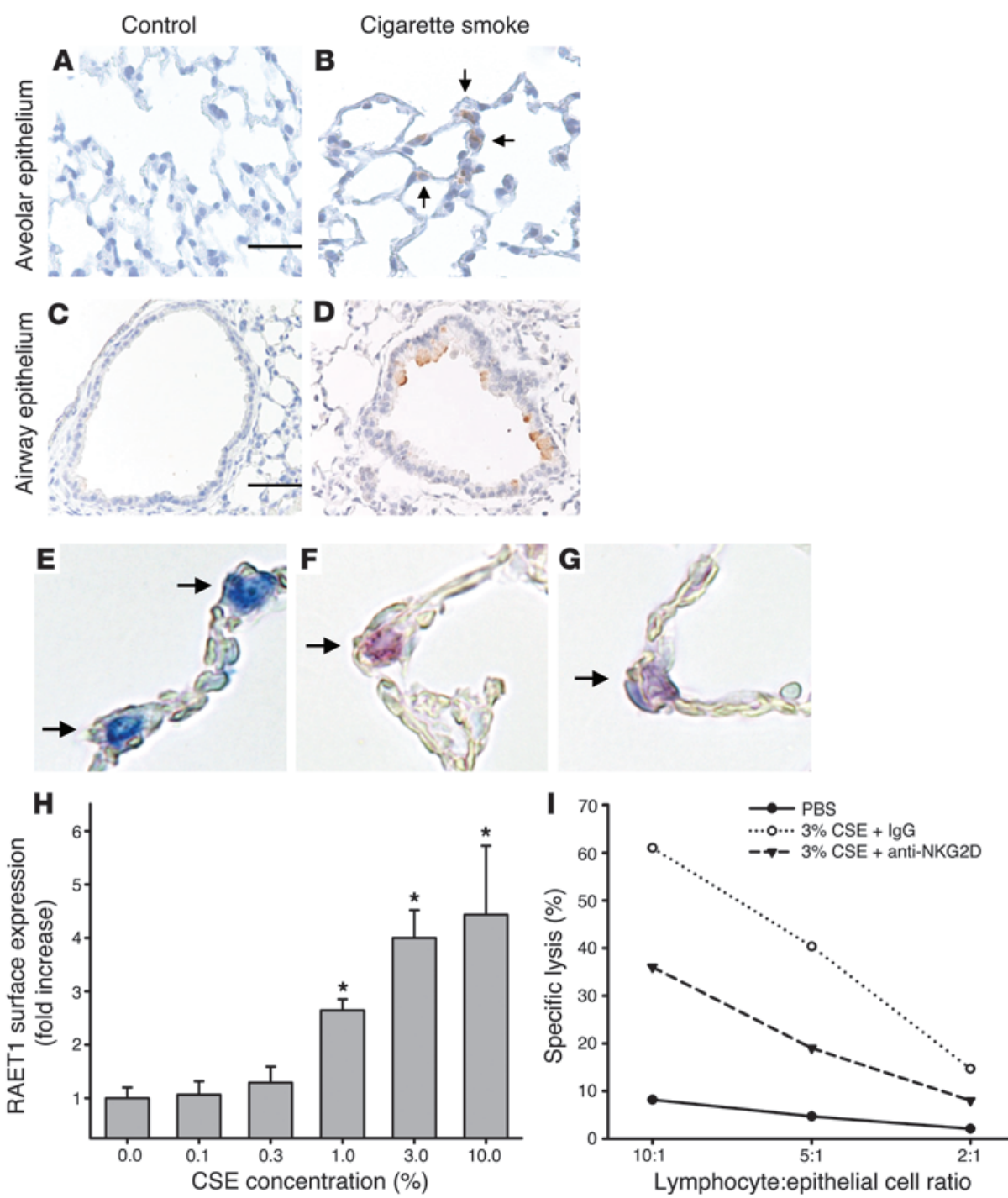

\section{Figure 1}

NKG2D ligands are induced on pulmonary epithelial cells in cigarette smokeinduced emphysema and mediate CTL activation. (A-D) RAET1 was assessed by immunohistochemistry in the alveolar and airway epithelium of mice exposed to filtered air (control; $\mathbf{A}$ and $\mathbf{C}$ ) or cigarette smoke (B and $\mathbf{D}$ ) for 6 mo. Arrows denote RAET1+ cells. Scale bars: $50 \mu \mathrm{m}$ (A and B); $100 \mu \mathrm{m}(\mathbf{C}$ and D). (E-G) Alveolar epithelial tissue sections of mice exposed to cigarette smoke were stained for pro-SPC (blue; E), RAET1 (red; F), or both (purple; G). Arrows indicate alveolar epithelial cells. Photomicrographs in A-G are representative of 5 mice per group. Original magnification, $\times 400$. (H) Primary mouse type II alveolar epithelial cells were isolated as described in Methods and treated with CSE or PBS for $24 \mathrm{~h}$. RAET1 expression was assessed by flow cytometry, and fold increase was derived from mean fluorescence intensity values. (I) Specific lysis of CSE-treated alveolar epithelial cells $\left(1 \times 10^{4}\right.$ cells $)$. Cells were cocultured with freshly isolated, strain-matched lymphocytes at the indicated ratios. Shown are PBS-treated epithelial cells, 3\% CSE-treated cells, and 3\% CSEtreated cells cocultured with lymphocytes treated with a monoclonal blocking antibody against the mouse NKG2D receptor. Data are results of 3 independent experiments performed in quadruplicate.
T cells, NK cells, NK T cells, and $\gamma \delta^{+} \mathrm{T}$ cells) and can directly induce cell cytolysis, enhance innate immune functions, and modulate adaptive immune responses. The role of this system in triggering immune responses might also influence pathways that can result in aberrant activation of the immune system, leading to autoimmunity or other forms of immunopathology (9). NKG2D ligands are not expressed in healthy adult tissues, but are induced by infection, transformation, and DNA damage (8, 10-14). Multiple families of structurally distinct NKG2D ligands have been identified in both humans and mice. Two families of NKG2D ligands have been identified in humans: the MHC class I chain-related (MIC) molecules MICA and MICB (15) and the UL-16 binding proteins (16-18). Ligands for the mouse NKG2D receptor are encoded by the retinoic acid-inducible early genes (Raet1a-Raet1e) (19), H60 (20), and Mult1 (21).

Recently, we demonstrated that NKG2D ligand expression is induced on pulmonary epithelial cells in response to oxidative stress and infection $(22,23)$, implicating NKG2D receptor activation as a mechanistic link between epithelial cell stress and lymphocyte activation in pulmonary tissues. In this study, we provide support for the hypothesis that persistent NKG2D-mediated activation of lymphocytes contributes to tissue remodeling and emphysema. In particular, we demonstrate that cigarette smoke induced NKG2D ligands on pulmonary epithelial cells and that NKG2D receptors governed cell-mediated cytotoxicity against cigarette smoke-exposed epithelial cells. We also show that sustained NKG2D activation was sufficient to cause pulmonary emphysema using a transgenic mouse model, which we believe to be novel, that regulates the exogenous expression of NKG2D ligands on pulmonary epithelial cells. Moreover, persistent epithelial expression of NKG2D ligands in mouse models of cigarette smoke-induced COPD and a population of COPD patients strongly correlated with morphological and physiological evidence of disease.

\section{Results}

Cigarette smoke induces NKG2D ligands in mouse pulmonary epithelium. Long-term exposure to cigarette smoke is the primary cause of COPD and, specifically, emphysema. We first examined whether cigarette smoke exposure induced expression of the mouse NKG2D ligand retinoic acid early transcript 1 (RAET1) in a mouse model of emphysema. Immunohistochemical analyses demonstrated that cigarette smoke exposure for 6 mo induced sustained RAET1 
expression in both airway epithelium and alveolar epithelium (Figure 1, A-D). We confirmed the expression of RAET1 on alveolar epithelial cells by dual labeling with the type II alveolar epithelial cell-specific marker pro-SPC (Figure 1, E-G).

RAET1 expression coincided with the development of emphysema, as determined by increased alveolar diameter. In contrast, RAET1 expression was not observed in control mice exposed to filtered air only. Quantitation of both RAET1 expression and increased alveolar diameter are presented below. Examination of NKG2D receptor expression in the lung revealed that approximately $20 \%$ of resident pulmonary lymphocytes express the NKG2D receptor (data not shown). This represents a substantial effector population, as lymphocytes accounted for about $2 \times 10^{5}$ to $5 \times 10^{5}$ cells in the mouse lung, and indicates that ligand upregulation is the limiting factor in this pathway.

To examine whether cigarette smoke exposure directly induces NKG2D ligand expression on pulmonary epithelial cells, we exposed primary mouse type II alveolar epithelial cells to cigarette smoke extract (CSE) and assessed RAET1 surface levels by flow cytometry. Untreated epithelial cells exhibited negligible expression of RAET1 ligands. However, similar to in vivo effects, CSE induced RAET1 surface expression (Figure $1 \mathrm{H}$ ).

NKG2D ligand induction on alveolar epithelial cells activates CTLs in vitro. To assess the functional significance of NKG2D ligand induction in response to cigarette smoke, we established a coculture system using mouse type II cells and syngeneic lymphocytes. CSE-treated epithelial cells elicited marked CTL activation compared with PBS-treated epithelial cells, as measured by specific lysis of epithelial cells (Figure 1I). To define the contribution of ligands for the NKG2D receptor in epithelial cell cytotoxicity, we preincubated the lymphocytes with a blocking antibody against the mouse NKG2D receptor prior to coculture with CSE-treated epithelial cells. Importantly, blocking NKG2D function reduced the cytolytic activity toward CSE-treated epithelial cells by approximately $50 \%$. These findings indicate that NKG2D ligand induction on alveolar epithelial cells is a major determinant of CTL activation after cigarette smoke exposure.

Transgenic overexpression of NKG2D ligands induces pulmonary emphysema. To characterize the response elicited by NKG2D ligands and their function in pulmonary pathophysiology, we generated a transgenic mouse model that allowed for the conditional expression of Raet1a in pulmonary epithelial cells. We expressed Raet1a in pulmonary epithelial cells under the control of doxycycline (DOX) administration using the ccsp-rtTA transgenic system previously described (24). We established 3 separate Raet1a Tg mouse lines (lines 20, 22, and 32) bearing the target (TetO) ${ }_{7}-\mathrm{CMV}$-Raet1a transgene. Line 20 Raet 1 a Tg mice failed to demonstrate Raet1a transcript induction after DOX administration. Line 32 Raet 1 a Tg mice demonstrated modest Raet1a transcript induction. Line 22 Raet1a Tg mice exhibited robust Raet1a transcript induction and were used in all subsequent studies unless otherwise indicated. Immunohistochemical staining of DOX-treated Raet1a Tg mice confirmed RAET1 expression throughout the airway and alveolar epithelium (Supplemental Figure 1; supplemental material available online with this article; doi:10.1172/JCI34462DS1) (25). None of the bitransgenic mice expressed the Raet1a transgene in the absence of DOX. Additionally, none of the bitransgenic mice exhibited any lung pathologies in the absence of DOX.

We first examined whether NKG2D ligand expression affected the composition of pulmonary leukocyte populations. Our data showed that RAET1 expression did not alter lung lymphocyte composition $\left(\mathrm{CD}^{+}, \mathrm{CD}^{+}, \mathrm{CD}^{+}, \gamma \delta^{+}\right.$, and NK cells) or the percentage of NKG2D+ lymphocytes (Figure 2A). Similarly, total and differential bronchoalveolar lavage (BAL) macrophage, neutrophil, and lymphocyte counts were not significantly different from those of control mice ( $P>0.6$ for all comparisons; Figure $2 \mathrm{~A})$.

Histological examination of the lungs of Raet1a Tg mice after DOX administration revealed that RAET1 expression caused a progressive destruction of the alveolar architecture, resembling pulmonary emphysema (Figure 2, B and C). Quantitation of the changes in airspace enlargement, as assessed by alveolar diameter, demonstrated a nearly $300 \%$ increase in airspace enlargement compared with control-treated transgenic mice. Tissue remodeling was primarily localized to the alveolar architecture, with moderate alterations of the epithelium in the terminal airways, after $60 \mathrm{~d}$ DOX administration (data not shown). Consistent with the development of an emphysematous phenotype, we also observed increased static and dynamic compliance, physiological parameters describing the loss of elastic recoil and lung distensibility (Figure 2, D and E). Similarly, pressure-volume curve analysis illustrated a loss of lung elasticity in Raet1 a Tg mice (Figure 2F).

We next examined whether the NKG2D receptor specifically mediated the effects of RAET1 expression by administering an antiNKG2D blocking antibody to Raet1 a Tg mice. We found that blocking NKG2D receptor activation completely abrogated the alveolar destruction observed in transgenic mice (Figure 2, B and G). These data strongly suggest that alveolar destruction, as a consequence of RAET1 expression, is mediated exclusively through the NKG2D receptor. Furthermore, we assessed the relative contributions of lymphocyte subpopulations to the alveolar destruction observed in Raet1a Tg mice. Elimination of NK cells using in vivo antibody depletion (anti-asialo GM1) significantly abated the effects of RAET 1 expression in this mouse model (Figure $2 \mathrm{G}$ ). In contrast, depletion of $\mathrm{CD}^{+}, \mathrm{CD}^{+}, \alpha \beta^{+}$, and $\gamma \delta^{+} \mathrm{T}$ cells had no significant effects on the development of airspace enlargement.

Transgenic overexpression of NKG2D ligands induces epithelial cell apoptosis and CTL activation, but not inflammation. Because NKG2D receptor activation can initiate several responses including inflammation, modulation of the adaptive immune response, and apoptosis of NKG2D ligand-expressing cells (8), we next sought to examine the possible contributions of these mechanisms to RAET1-induced emphysema. Assessments of bioactivity of the apoptotic markers active caspase 3 (Casp3) and Casp3/7 revealed that the apoptosis signals in the lungs of Raet $1 \mathrm{a} \mathrm{Tg}$ mice were increased (Figure 3, $\mathrm{A}$ and $\mathrm{B})$. Immunohistochemistry revealed that the active Casp $3^{+}$ cells primarily localized to the alveolar compartments, consistent with the emphysematous phenotype. We assessed CTL activation by measuring the apoptotic effector enzyme granzyme B. Consistent with a role in CTL activation during epithelial cell apoptosis, we observed increased granzyme B protein levels in Raet1a Tg lungs both before and during the development of alveolar destruction (Figure 3C). These data are consistent with the results obtained with cigarette smoke-induced NKG2D ligand induction and CTL activation. That is, induction of NKG2D ligands activates the pulmonary immune system and leads to the destruction and/or removal of pulmonary epithelial cells.

Because MMPs are thought to play a critical role in the development of emphysematous lesions in mouse models (26), we assessed the activation state of the pulmonary macrophage compartment by examining MMP2 and MMP9 activation by gelatin zymography. 
A

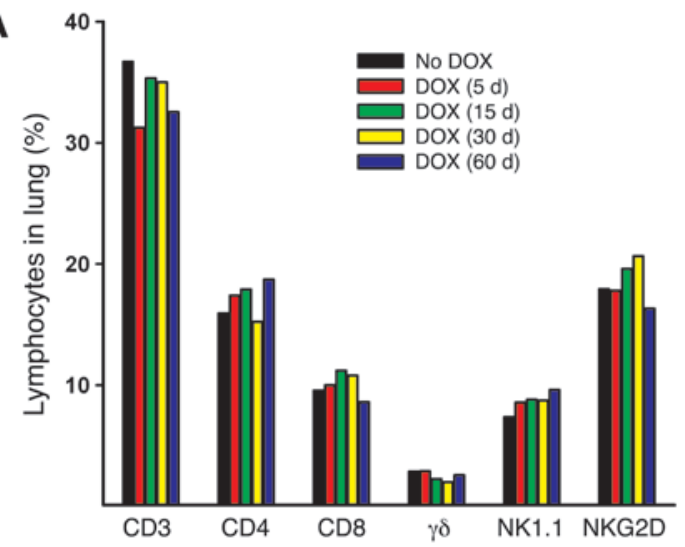

B
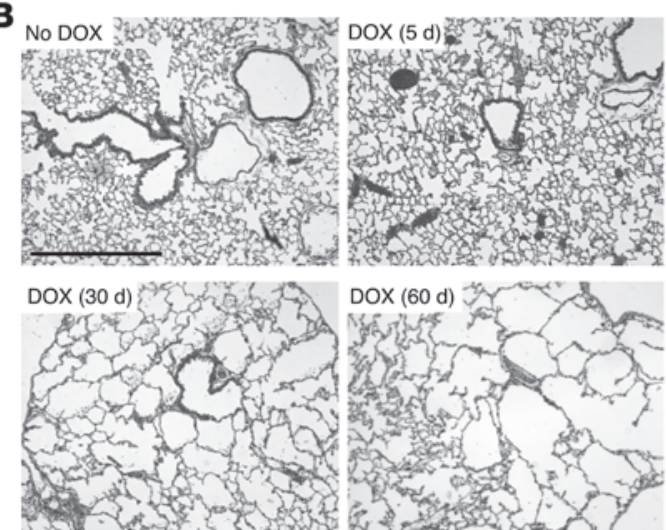

D

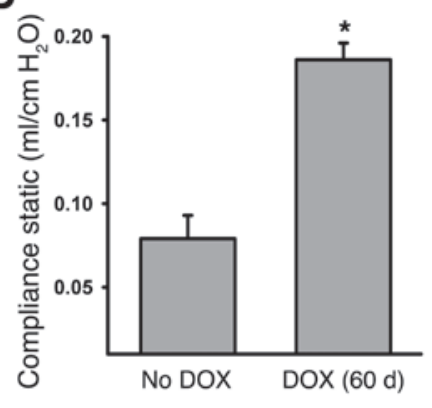

$\mathbf{E}$

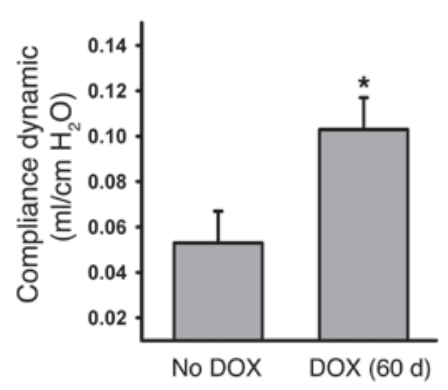

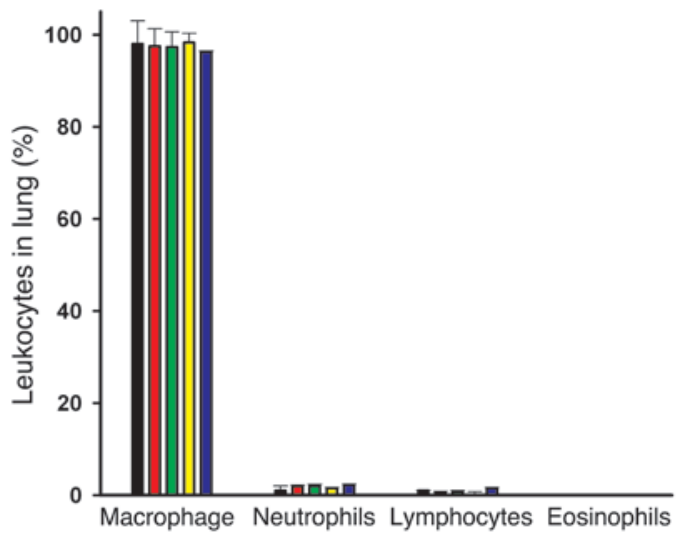
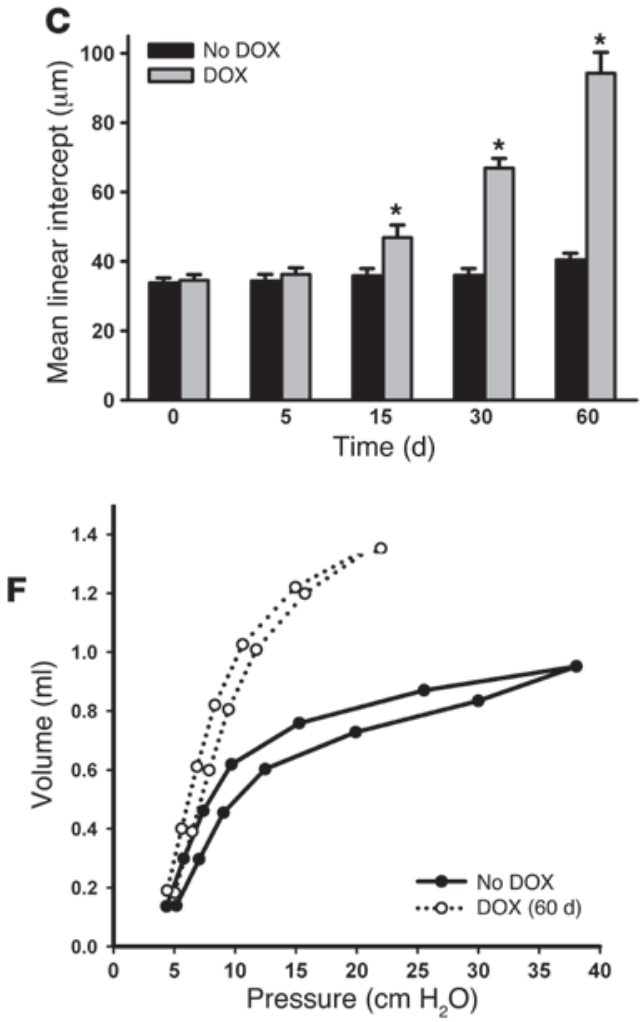

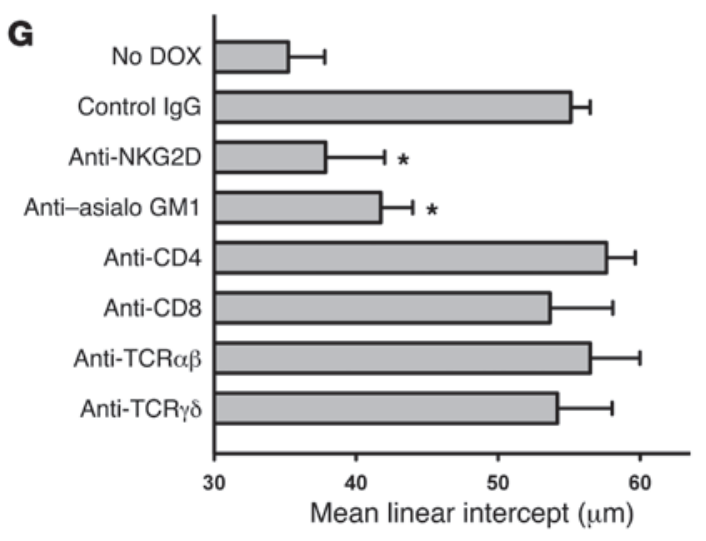

Figure 2

In Raet1a Tg mice, inducible expression of RAET1 on pulmonary epithelial cells leads to pulmonary emphysema. (A) Lymphocyte populations in digested whole lungs of mice given DOX for the indicated times were quantitated by flow cytometry using antibodies specific for the indicated cell surface markers. Data are results of 3 independent experiments using pooled samples from at least 3 mice per group. Inflammatory cells in the lung were assessed by enumeration of cell differentials in the BAL ( $n=5$ per group). (B) H\&E-stained lung sections from mice that were left untreated, administered DOX for $5,15,30$, and $60 \mathrm{~d}$, or administered $30 \mathrm{~d}$ DOX concurrently with an NKG2D blocking antibody. Photomicrographs are representative of 5 mice per group. Scale bar: $100 \mu \mathrm{m}$. (C) Time course of alveolar destruction, quantified as mean linear intercept. (D-F) Mice were administered DOX for $60 \mathrm{~d}$, and static compliance (D), dynamic compliance (E), and pressure-volume loops (F) were determined using a forced oscillation technique. These functional indicators of elastic recoil loss reflect the ease with which the lung distends. Values are mean \pm SD ( $n=3-5$ per group). (G) Specificity for NKG2D-mediated effects ( $n=5$ per group). Lymphocyte populations were specifically depleted as described in Methods, and mean linear intercept was assessed after $30 \mathrm{~d}$ DOX treatment. ${ }^{*} P<0.05$ versus respective no DOX control. 
A

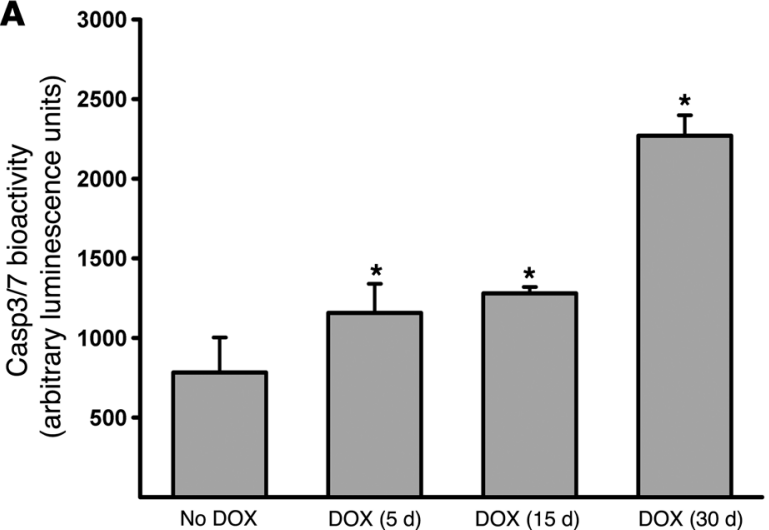

B
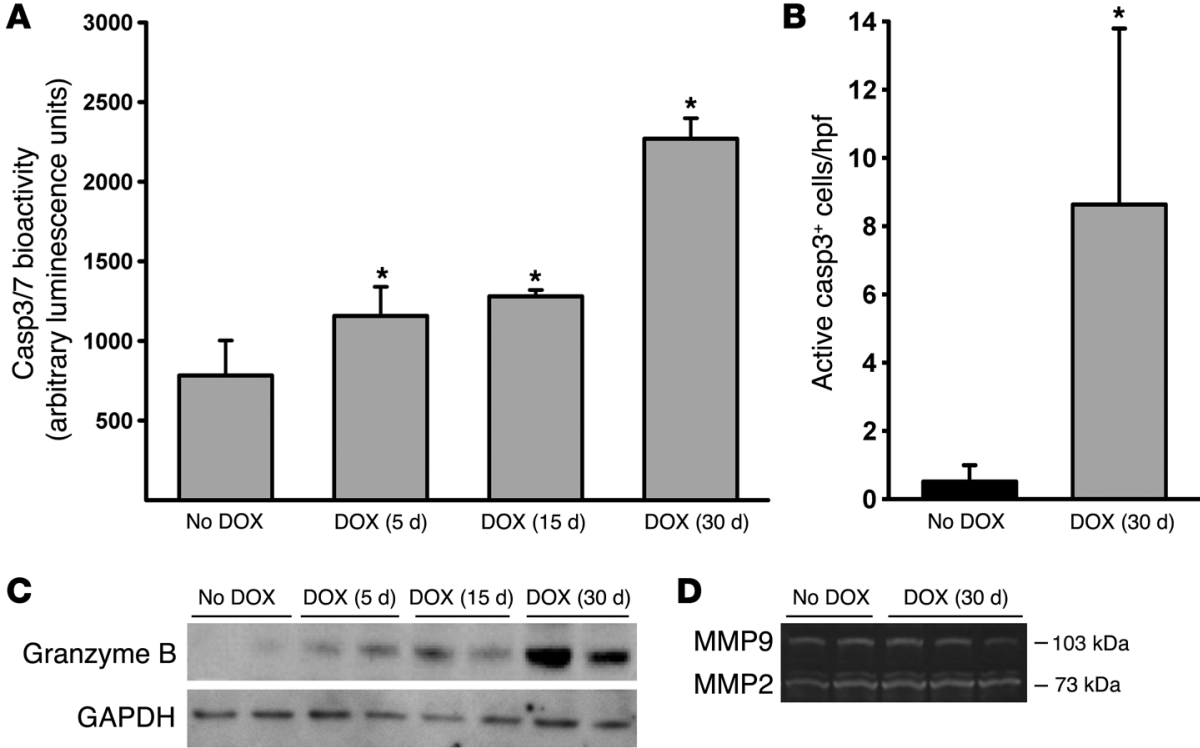

$\mathbf{E}$

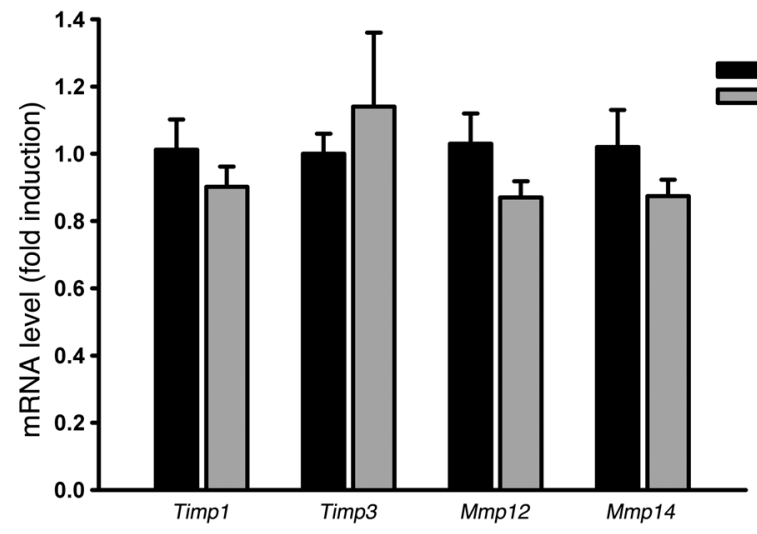

Figure 3

Transgenic overexpression of NKG2D ligands induces epithelial cell apoptosis and CTL activation. (A) Effector caspase expression in lungs of Raet1a Tg mice administered $30 \mathrm{~d}$ DOX was assessed by $\mathrm{Casp} 3 / 7$ bioactivity in whole lung homogenates ( $n=5$ per group). (B) Apoptotic cell accumulation in the lungs was assessed by immunohistochemistry on paraffin-embedded sections using a rabbit antibody specific for active Casp3. The number of active Casp $^{+}-$stained cells was quantified from photomicrographs of lung sections and presented as mean \pm SD cells per high-power field (hpf). (C) CTL effector function was induced by NKG2D ligand expression in vivo. Western blot analysis on whole lung homogenates using a granzyme B-specific antibody showed increased protein expression after NKG2D ligand induction in pulmonary epithelial cells. (D) MMP2 and MMP9 activity were not altered in the lungs of mice ectopically expressing RAET1. Gelatin zymography was conducted on lung homogenates of Raet1a Tg mice left untreated $(n=2)$ or treated with $30 \mathrm{~d}$ DOX $(n=3)$. Photomicrograph is representative of results obtained from 4-6 mice per group. (E) Transcript levels for MMP inhibitors Mmp12 and Mmp14 were not altered in the lungs of mice ectopically expressing RAET1. Real-time quantitative PCR was performed on RNA isolated from the lungs of Raet1a Tg mice left untreated or treated with $30 \mathrm{~d}$ DOX ( $n=5$ per group). ${ }^{*} P<0.05$ versus no DOX control.
Raet 1 a Tg mice failed to demonstrate an increase in MMP2/9 activity, which coincided with the development of airspace enlargement (Figure 3D). Additionally, we measured the transcript levels of Mmp12, Mmp14, tissue inhibitor of metalloproteinases 1 (Timp1), and Timp3. Raet 1 a $\mathrm{Tg}$ mice failed to demonstrate an increase in these mediators, coinciding with the development of airspace enlargement (Figure 3E). Together, these data indicate that transgenic expression of RAET1 does not result in perturbations of the lymphocyte or macrophage populations known to contribute to airspace enlargement in smoke-induced emphysema models. Additionally, the lack of any effects on cell composition in these compartments, along with the data demonstrating activation of CTLs (i.e., granzyme B), suggests that the mechanism of alveolar destruction involves the efficient removal of affected cells without leading to collateral effects (i.e., inflammation).

Sustained RAET1 expression correlates with increased alveolar destruction in multiple models of pulmonary emphysema. To identify whether there is a relationship between the persistent expression of RAET1 and the development of airspace enlargement, we measured these endpoints in multiple models of airspace enlargement (Figure 4). These models included Raet1a Tg lines (strain FVBN background), mice exposed to cigarette smoke (strain $\mathrm{BALBc} / \mathrm{J}$ ), and a model of acrolein-induced COPD (strain C57BL/6J) that we recently described (27). These data illustrate that there is a dose response relationship between the number of RAET $1^{+}$epithelial cells and the degree of airspace enlargement $\left(r^{2}=0.96, P=0.001\right)$.

$N K G 2 D$ ligand expression increases in the peripheral lung of COPD patients and is associated with the development of COPD pathologies. To further investigate the potential role of NKG2D in COPD, we examined the pulmonary expression of an NKG2D ligand, MICA, in human subjects with and without disease and assessed its association with several clinical components of the disease. Immunoblot analysis from peripheral lung resections demonstrated that protein levels of MICA were significantly increased in COPD patients (Figure 5, A and B). MICA expression was not detected in liver specimens from patients, regardless of COPD diagnosis (data not shown), which suggests that MICA upregulation is not a ubiquitous feature in tissues obtained from COPD patients.

Because cytotoxic $\mathrm{CD}^{+}$and NK lymphocytes and their functional proteases are localized to the small airways (28) and to the lung parenchyma (29), we quantitated the abundance of $\mathrm{T}$ cell subpopulations, $\mathrm{NK}$ cells $\left(\mathrm{CD} 56^{+}\right)$, and $\mathrm{NKG}_{2} \mathrm{D}^{+}$cells in peripheral lung tissue of non-COPD and COPD patients undergoing thoracic surgery. Flow cytometric analyses indicated that NKG2D receptors were expressed on greater than $50 \%$ of peripheral lung lymphocytes (Figure 6A). However, the percent of $\mathrm{NKG}^{2} \mathrm{D}^{+}$cells 


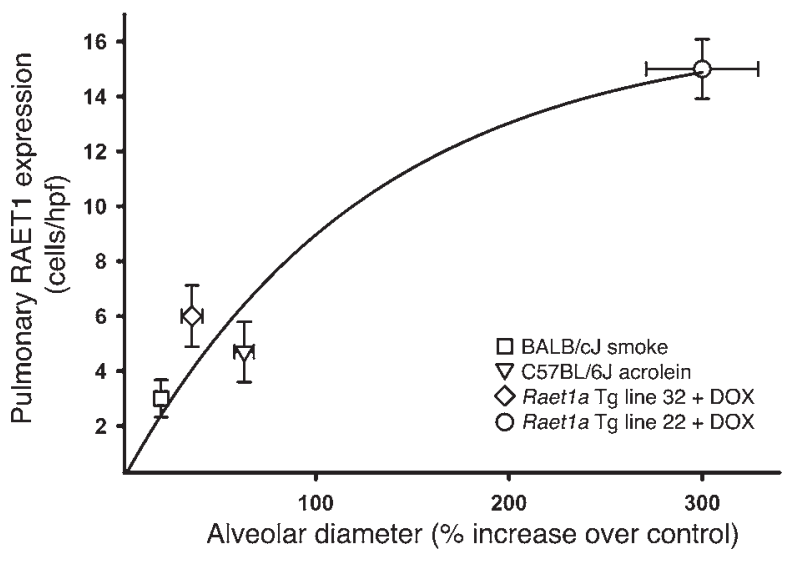

was not different between groups (Figure 6B). In addition, NK cells, which universally express NKG2D (8), represented greater than $30 \%$ of the peripheral lung lymphocyte population. Phenotyping of $\mathrm{CD}^{+} \mathrm{T}$ cells showed that greater than $90 \%$ of cytotoxic $\mathrm{CD}^{+} \mathrm{T}$ cells were $\mathrm{NKG} 2 \mathrm{D}^{+}$, whereas fewer than $5 \%$ of $\mathrm{CD} 4^{+} \mathrm{T}$ cells expressed NKG2D (Figure 6, C-E).

To further examine the relationship between NKG2D ligand expression and the development of COPD pathologies, we assessed MICA expression in bronchial biopsies from 93 patients (21 never smokers, 30 former smokers, and 42 current smokers). These patients were extensively characterized in terms of pulmonary function, lung cancer staging, and presence of bacteria in bronchoaspirate cultures. MICA staining in bronchial biopsies from current and former smokers was present in the apical and basolateral membranes as well as airway epithelial cell cytoplasm (Figure 7, A-H). Analysis of MICA expression in the alveolar unit revealed a more diffuse pattern, possibly reflecting the expression in vascular endothelium (Figure 7I). Risk estimations indicated that sex, cigarette smoking, chronic bronchitis symptoms, and COPD diagnosis were all strongly associated with MICA expression in the airway epithelium (Table 1; see Methods and Supplemental Figure 2 for delineation of $\mathrm{MICA}^{+}$and $\mathrm{MICA}^{-}$categorical variables). The forced expiratory volume in the first second, a marker of airflow obstruction, and the lung transfer capacity for $\mathrm{CO}\left(\mathrm{TL}_{\mathrm{CO}}\right)$, a marker of pulmonary emphysema, were significantly decreased in $\mathrm{MICA}^{+}$ patients (Table 1). Moreover, macroscopic evidence of emphysema of the lungs, evident in $21(23 \%)$ of the patients with an available CT scan of the lungs $\left(n=87\right.$ ), was associated with decrease of $\mathrm{TL}_{\mathrm{CO}}$ (evident emphysema, $67 \pm 14$; versus nonevident emphysema, $83 \pm 22$; $P=0.009$ ), $\mathrm{CO}$ transfer coefficient ( $\mathrm{K}_{\mathrm{CO}}$, equal to $\mathrm{TL}_{\mathrm{CO}}$ normalized to effective alveolar volume; $75 \pm 13$ versus $92 \pm 19 ; P=0.001)$, and

\section{Figure 4}

NKG2D ligand expression on pulmonary epithelial cells correlates with increased alveolar diameter in multiple mouse models of emphysema. The abundance of RAET1 expression on pulmonary epithelial cells was plotted against the increase in alveolar diameter (mean linear intercept) compared with respective control mice in 3 experimental models of pulmonary emphysema. RAET1 expression and mean linear intercept were quantified as described in Methods. The statistical significance of the relationship between RAET1 and increased alveolar diameter in these models is $P<0.001$.

BMI $(22 \pm 5$ versus $26 \pm 3 ; P=0.01)$. A near significant association was found between definite macroscopic emphysema and expression of MICA $(P=0.07)$. MICA expression associated with the presence of lung cancer, but not with other variables, including age, cancer staging, or evidence of bacterial infection (Table 1).

Although endobronchial biopsies are not the target tissue in regard to the development of emphysema, we evaluated these specimens for several reasons. COPD is a complex mixture of both pulmonary emphysema and chronic bronchitis, and it is reasonable to assume that changes in the airways of patients with COPD are reflective and predictive of changes in the peripheral lung (30). Moreover, we could obtain reasonable access to endobronchial biopsies, as opposed to the peripheral lung, in larger study patient groups. Therefore, we examined biopsies of peripheral lung tissues available in the limited subgroup of COPD cases and non-COPD controls that were submitted to thoracic surgery $(n=17)$. All samples that demonstrated $\mathrm{MICA}^{+}$endobronchial biopsies $(n=6)$ were also $\mathrm{MICA}^{+}$in the alveolar epithelium.

\section{Discussion}

A potential role for lymphocytes in COPD pathologies is based primarily on reports demonstrating that the number of lymphocytes in the lung correlates with the extent of COPD clinical endpoints (31-34). However, the mechanism whereby lymphocytes become activated and contribute to COPD pathologies remains unclear. In the present study, we provide evidence, which we believe to be novel, that a lymphocyte activation pathway, NKG2D ligand expression, is associated with COPD pathologies in mouse models of disease and in human patients. Furthermore, we demonstrated that pulmonary expression of NKG2D ligands is sufficient for the development of emphysema in a mouse model.

\section{Figure 5}

MICA protein expression is increased in peripheral lung tissue of COPD patients. (A) MICA protein levels in peripheral lungs of non-COPD and COPD patients were assessed by immunoblot analysis. (B) Relative expression of individual MICA and $\beta$-actin bands were quantitated by scanning densitometry and expressed as a ratio of MICA to $\beta$-actin. Values are mean \pm SD. ${ }^{*} P<0.05$ versus non-COPD.
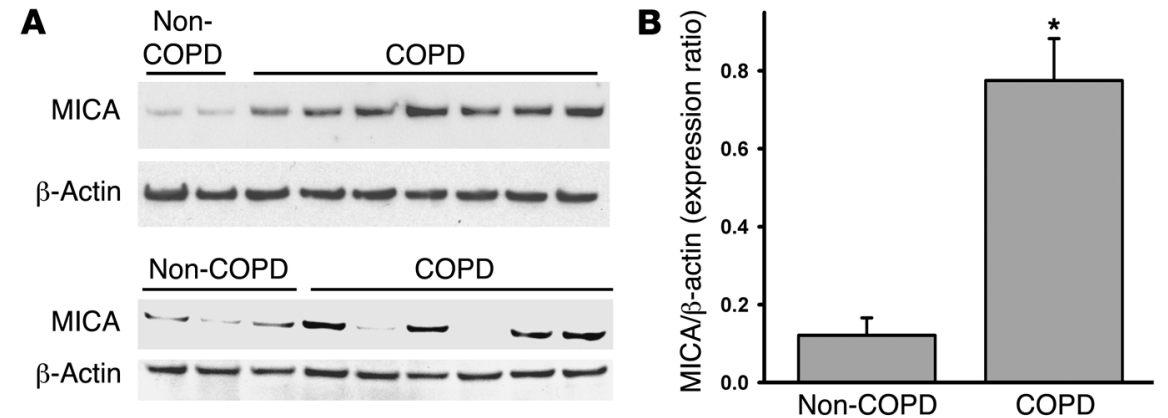
A

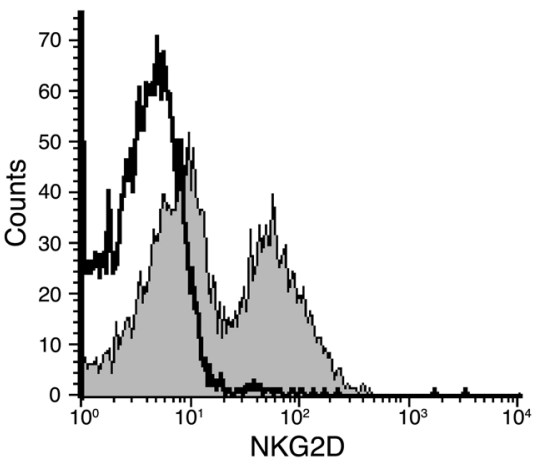

B

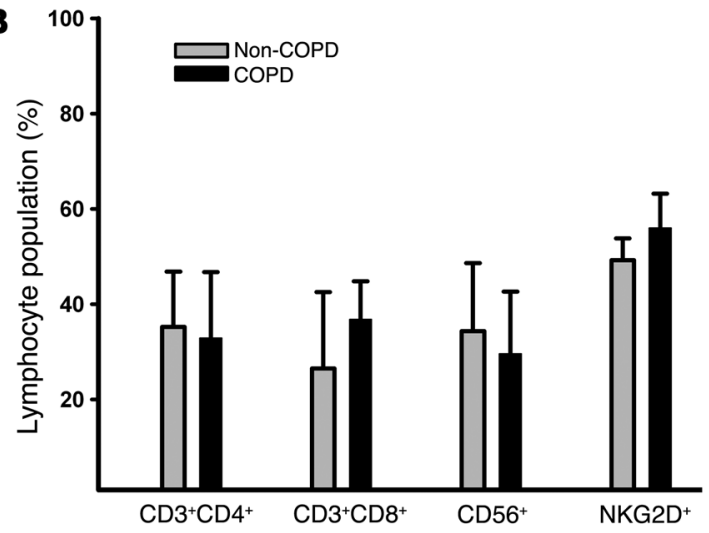

C

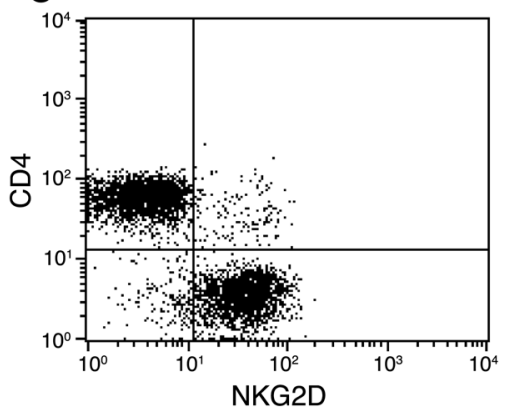

D

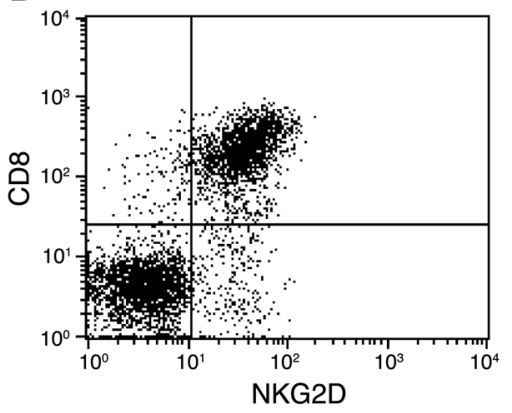

E

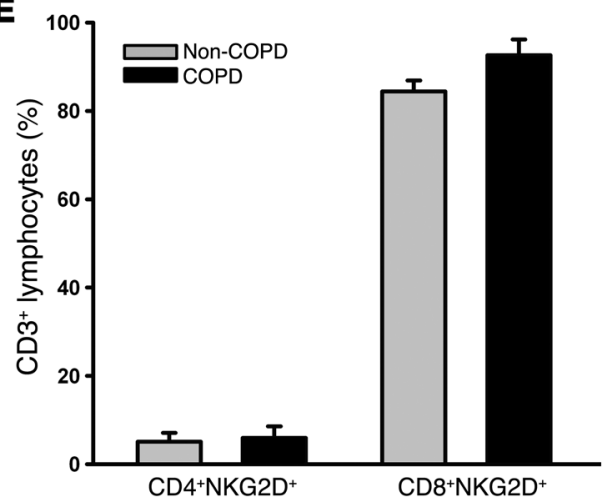

Figure 6

NKG2D receptors are constitutively expressed on pulmonary CTLs. (A) NKG2D receptor expression on lymphocytes isolated from peripheral lung tissue of a representative COPD patient. Lymphocyte population was defined by forward and side scatter properties. Open histogram represents isotype control staining; filled histogram represents anti-NKG2D staining. (B) Relative abundance of CD3+CD4+, CD3 ${ }^{+} \mathrm{CD} 8^{+}, \mathrm{CD}^{+} 6^{+}(\mathrm{NK})$, and NKG2D+ lymphocytes in the peripheral lungs of non-COPD and COPD patients. (C and D) CD4+NKG2D+ T cells (C) and CD8+NKG2D+ T cells (D) isolated from peripheral lung tissue of a representative COPD patient gated on $\mathrm{CD}^{+}$cells. (E) Relative abundance of $\mathrm{CD} 3^{+} \mathrm{CD} 4{ }^{+} \mathrm{NKG} 2 \mathrm{D}^{+}$and $\mathrm{CD}^{+}{ }^{+} \mathrm{CD} 8{ }^{+} \mathrm{NKG} 2 \mathrm{D}^{+} \mathrm{T}$ cells in the peripheral lungs of non-COPD and COPD patients. Values are mean \pm SD. $n=5$ (non-COPD); 10 (COPD).

Based on our experimental findings, we postulate that sustained expression of NKG2D ligands leads to the disruption of the alveolar architecture by CTL-mediated apoptosis of pulmonary epithelial cells. Given that NKG2D-bearing cells were abundant in the lung and that NKG2D lymphocyte populations did not considerably change in our mouse models of emphysema or COPD patients, we conclude that the mechanisms controlling this pathway are primarily dependent on the anomalous, sustained expression of NKG2D ligands on pulmonary epithelial cells and are independent of NKG2D receptor regulation. Several lines of evidence from in vitro and in vivo models demonstrate that the NKG2D pathway directly contributes to the pathogenesis of COPD. First, we showed that NKG2D ligands were not constitutively expressed in pulmonary epithelial cells of healthy subjects or naive mice, but cigarette smoke exposure associated with NKG2D ligand expression in both airway and peripheral tissues. Second, we showed that cell-mediated cytotoxicity against cigarette smoke-exposed alveolar epithelial cells was dependent on NKG2D receptor signaling. Third, transgenic expression of NKG2D ligands by pulmonary epithelial cells resulted in increased apoptosis of epithelial cells and emphysema, which was critically dependent on the function of NKG2D and NK cells. Fourth, we used multiple mouse models of emphysema to establish a causal relationship between NKG2D ligand expression and the typical histological changes of emphysema.

The mechanisms regulating NKG2D-mediated effector functions have been thoroughly characterized (reviewed in ref. 35). NKG2D engagement is dependent on DAP10/DAP12 adaptor molecules that recruit Src family kinases and initiate multiple downstream signaling pathways that culminate in granule polarization, cytokine release, and cytotoxicity. In addition to ligand engagement, the expression and function of NKG2D can be influenced by other factors in the immune microenvironment, including IL-15 (36), IL-21 (37), and TGF- $\beta 1$ (38). However, the number of effector lymphocytes expressing the NKG2D receptor was not affected by increased NKG2D ligand expression. Our present study as well as previous studies by others $(28,29)$ demonstrate that CTLs, including NKG2D+ lymphocytes, are constitutively present in substantial numbers in the lung parenchyma. The differences in NKG2D receptor expression between mouse and human pulmonary lymphocytes represent a salient consideration in the interpretation of the data presented in the present study. In humans, NKG2D is present on the majority of $\mathrm{CD}^{+} \mathrm{T}$ cells and NK cells. In contrast, NKG2D is expressed primarily on NK cells, but not $\mathrm{CD}^{+} \mathrm{T}$ cells, in mice. Therefore, our data demonstrating that NK cell depletion, but not $\mathrm{CD}^{+} \mathrm{T}$ cells, ablated RAET1-mediated alveolar destruc- 
Isotype control (current smoker with COPD)
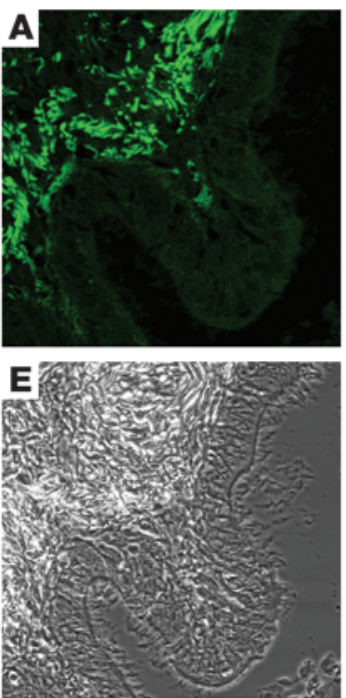

I
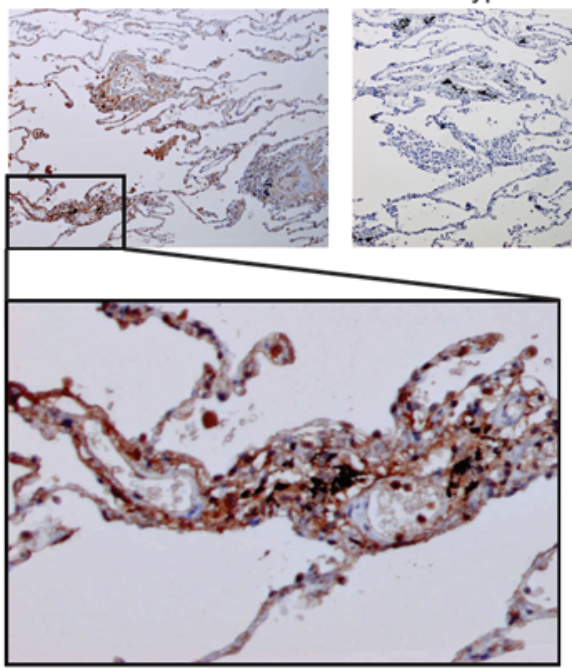

$\alpha$-MICA

(current smoker with COPD)
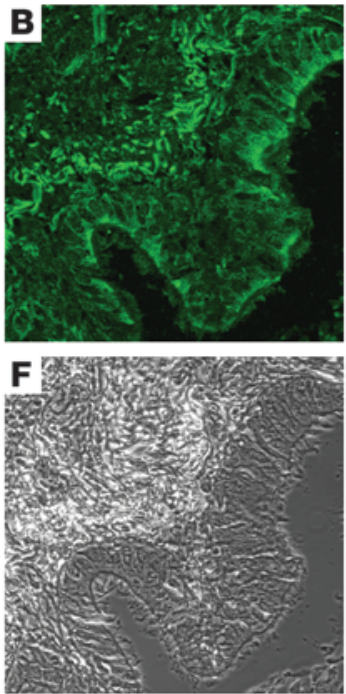

Isotype control

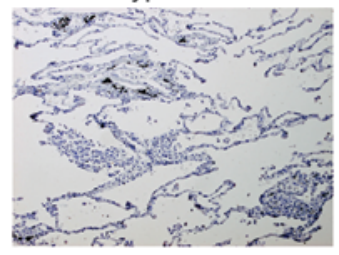

20in tion in the transgenic mouse model may not represent a congruent response in human disease. It is more likely that the response to NKG2D ligands in humans is also mediated by the effector functions of $\mathrm{CD}^{+} \mathrm{T}$ cells and includes potentially confounding factors such as concurrent $\mathrm{T}$ cell receptor activation and the impact of pathogen-based disease exacerbations (39). We conclude that induced NKG2D ligand expression, as opposed to receptor expression, is the major determinant of NKG2D-attributed pathologies in COPD. This conclusion is supported by observations that nonsmokers had no MICA expression, but expressed the same proportion of NKG2D ${ }^{+}$CTLs, compared with COPD patients. Moreover, exogenous RAET1 expression in pulmonary epithelial cells caused an emphysematous phenotype without altering the CTL number in the parenchyma. Our conclusion is also bolstered by the lack of modulation of NKG2D ${ }^{+}$cells observed in both cigarette smokeexposed mouse lungs and Raet1a Tg mice, and the lack of pulmonary inflammation or macrophage activation (as evidenced by MMP activation) observed in mice expressing exogenous RAET1.

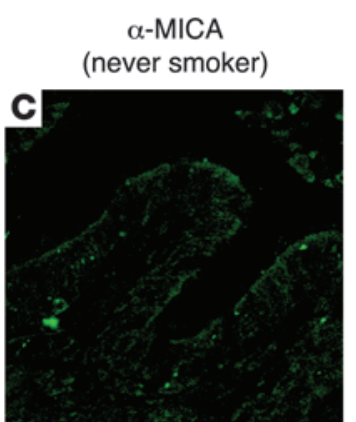

$\alpha-\mathrm{MICA}$
(former smoker with COPD)
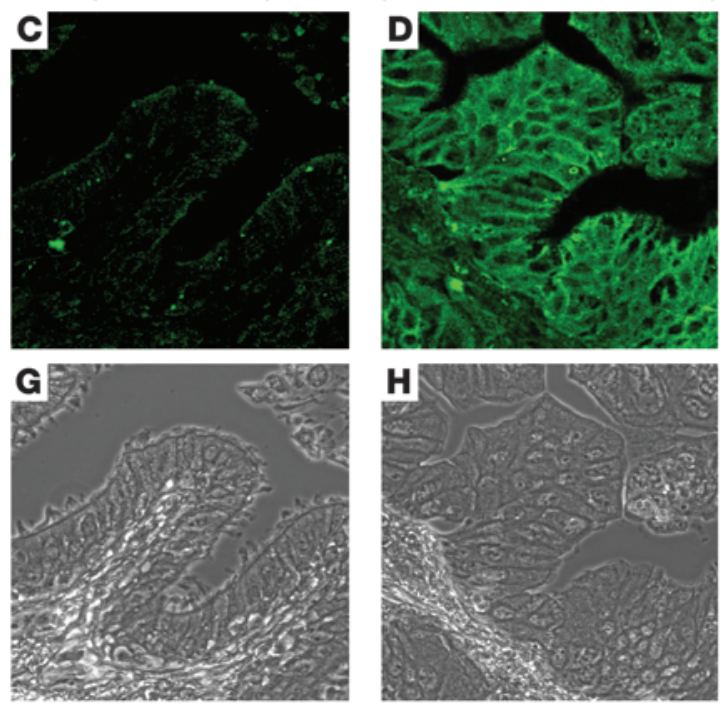

\section{Figure 7}

MICA expression is associated with the development of COPD. (A-D) MICA expression in airway epithelium and alveolar epithelium was assessed by immunohistochemistry. Immunofluorescent detection of MICA expression in the bronchial epithelium was assessed by confocal microscopy in current smokers with COPD (A and B are serial sections from same patient to demonstrate isotype control staining reaction), never smokers (C), and former smokers with COPD (D). Representative images are shown. $(\mathbf{E}-\mathbf{H})$ Phase contrast images were obtained by confocal microscopy using the same settings. (I) MICA localization in the alveolar epithelium was assessed by light microscopy in the peripheral lung of a current smoker with COPD. Original magnification, $\times 40$; $\times 200$ (inset in I).

The apparent lack of MICA expression in some smokers and COPD patients is intriguing. Current paradigms of complex disease pathogenesis, including COPD, incorporate multiple factors and pathways and include the possibility of interactions among them. The absence of MICA in a subgroup of smokers and COPD patients could be a reflection of several possibilities. These include an actual absence of MICA in some patients, attributable to interindividual variability in response to exposures inherent to any biological process; potential anatomical heterogeneity of the MICA expression (i.e., a negative biopsy obtained from an anatomical location does not exclude MICA expression in other airways); expression levels below our detection limits, and the potential involvement of other NKG2D ligands, such as ULBP proteins. The presence of aberrant polymorphic MICA alleles may circumvent detection with the antibody and also contributes to a failure to detect MICA expression (40). For example, the MICA-A5.1 allele has 1 extra nucleotide in the transmembrane region compared with the MICA-A5, which leads to a frame shift. This results in 
Table 1

MICA expression in bronchial epithelium according to demographic and clinical characteristics

\begin{tabular}{|c|c|c|c|c|}
\hline & Total & MICA- & $\mathrm{MICA}^{+}$ & $P$ \\
\hline \multicolumn{5}{|l|}{ General characteristics } \\
\hline$n$ & 93 & 56 & 37 & \\
\hline Sex (male/female) & $75 / 18$ & $40 / 16$ & $35 / 2$ & 0.006 \\
\hline Age (yr) & $66 \pm 11$ & $67 \pm 10$ & $65 \pm 11$ & 0.28 \\
\hline \multicolumn{5}{|l|}{ Smoking status } \\
\hline Never smoker & 21 & 21 & 0 & \\
\hline Former smoker & 30 & 18 & 12 & \\
\hline Current smoker & 42 & 17 & 25 & 0.000 \\
\hline \multicolumn{5}{|l|}{ COPD and smoking $A$} \\
\hline Non-COPD never smoker & 15 & 15 & 0 & \\
\hline Non-COPD former smoker & 4 & 4 & 0 & \\
\hline Non-COPD current smoker & 7 & 2 & 5 & $0.004^{B}$ \\
\hline COPD never smoker & 6 & 6 & 0 & \\
\hline COPD former smoker & 26 & 14 & 12 & \\
\hline COPD current smoker & 35 & 15 & 20 & $0.034^{C}$ \\
\hline \multicolumn{5}{|l|}{ Chronic bronchitis } \\
\hline No & 47 & 37 & 11 & \\
\hline Yes & 46 & 19 & 26 & 0.000 \\
\hline \multicolumn{5}{|l|}{ Pulmonary function } \\
\hline $\mathrm{FEV}_{1}(\%$ predicted $)$ & $67 \pm 23$ & $71 \pm 25$ & $61 \pm 19$ & 0.041 \\
\hline FVC (\% predicted) & $73 \pm 18$ & $77 \pm 20$ & $69 \pm 19$ & 0.171 \\
\hline $\mathrm{FEV}_{1} / \mathrm{FVC}$ ratio & $65 \pm 12$ & $66 \pm 13$ & $64 \pm 10$ & 0.249 \\
\hline TLC (\% predicted $)$ & $95 \pm 19$ & $97 \pm 20$ & $93 \pm 19$ & 0.351 \\
\hline $\mathrm{TL}_{\mathrm{co}}(\%$ predicted $)$ & $78 \pm 22$ & $86 \pm 22$ & $68 \pm 16$ & 0.005 \\
\hline \multicolumn{5}{|l|}{ Macroscopic emphysema ${ }^{D}$} \\
\hline Nonevident & 66 & 43 & 23 & \\
\hline Evident & 21 & 9 & 12 & 0.070 \\
\hline \multicolumn{5}{|l|}{ Lung cancer } \\
\hline Negative & 31 & 25 & 6 & \\
\hline Positive & 62 & 31 & 31 & 0.004 \\
\hline \multicolumn{5}{|l|}{ Bronchoaspirate culture $\mathrm{E}$} \\
\hline Negative & 58 & 35 & 23 & \\
\hline Positive & 35 & 21 & 14 & 0.974 \\
\hline
\end{tabular}

Age and pulmonary function values are mean \pm SD; other values denote $n$. $\mathrm{FEV}_{1}$, forced expiratory volume in $1 \mathrm{~s} ; \mathrm{FVC}$, forced vital capacity; TLC, total lung capacity. ${ }^{A} P=0.000$, non-COPD versus $C O P D$ groups. ${ }^{B}$ Among smoking statuses in non-COPD group. ${ }^{C} A m o n g$ smoking statuses in COPD group. DAs assessed by CT scan; 6 scans were not available. EBacteria species included $S$. flora, $P$. aeruginosa, $H$. influenza, S. pneumoniae, S. aureus, S. marcescens, and M. tuberculosis.

a premature stop codon within the transmembrane region, and, consequently, no cytoplasmic tail is present in these MICA molecules, which can lead to aberrant expression on the cell surface. Furthermore, we cannot exclude the possibility that smokers without a COPD diagnosis that demonstrate MICA expression in the epithelium are absolutely free of pulmonary disease. According to present definitions, diagnosis of airflow obstruction and COPD itself is based on pulmonary function tests, mainly spirometry. Nevertheless, several studies demonstrate that high-resolution CT is more sensitive and specific than commonly used functional tests for the evaluation of initial emphysema in asymptomatic smokers, despite normal or minimal abnormal changes in spirometry, $\mathrm{TL}_{\mathrm{CO}}$, or other variables $(41,42)$. In other words, we speculate that it is probable that the definition of COPD according to current guidelines, and hence assignation of our volunteers to one group, could underestimate the presence of early phases or less obstructive phenotypes of the disease. Additionally, the potential abrogation of bronchial MICA expression in response to chronic inhaled treatment may confound the detection of ligand expression, as most COPD patients receive inhaled $\beta$-adrenergic and inhaled steroids that potentially regulate epithelial cell gene expression. Finally, interindividual variability in treatment compliance may also represent a variable explaining potential MICA downregulation in some COPD patients.

The results of the present study indicate that the progressive alveolar destruction observed in Raet1a Tg mice is primarily a consequence of directed cytotoxicity against RAET $1^{+}$cells. This response was associated with an increase in perforin/granzyme activity that was accompanied by an increase in apoptotic pulmonary epithelial cells. These results were not surprising, because previous studies have demonstrated that exogenous expression of NKG2D ligands elicits perforin/granzyme-mediated cytolysis in vitro (43, 44). However, these findings represent an expansion of earlier studies investigating the role of CTLs in COPD. Along these lines, increased expression of perforin, a pore-forming protein that causes apoptosis of target cells via cytolytic granules, has previously been reported in CTLs in patients with COPD (45), and increased alveolar epithelial cell apoptosis is correlated with the number of CTLs in patients with emphysema (34). In addition, recent studies demonstrate that cytotoxic $\mathrm{T}$ cells are necessary for the development of toxicantinduced emphysema in mice $(27,46)$.

Our findings of no major alterations in the cellular composition of the BAL or whole lung compartments of Raet1a Tg mice coincident with the development of alveolar destruction were somewhat unexpected. NKG2D receptor activation in vitro results in the elaboration of several cytokines (IFN- $\gamma$, TNF- $\alpha$, IL-2, IL4, and GM-CSF; refs. 16, 47), and chemokines (macrophage inflammatory protein $1-\beta$ and I-309; refs. $16,48,49)$ that are capable of inducing the accumulation and activation of multiple leukocyte populations. Therefore, the lack of BAL and lung inflammation in Raet 1 a Tg mice suggests that the binding of mouse NKG2D by RAET1 in vivo elicits a fundamentally different response than that observed in vitro (i.e., inflammatory cytokine elaboration), or that these mediators are not produced in sufficient quantities in vivo to induce overt inflammation. The implication of these findings is that the effector function of RAET1 expression and/or NKG2D receptor activation is downstream of both the inflammation and excess proteolytic activity observed in the natural progression of pulmonary emphysema. It is important to emphasize that this is not necessarily the same expectation we would have for the effects of endogenous NKG2D ligand expression induced in a toxicantinduced model of airspace enlargement. In the instance of endogenous induction by cigarette smoke exposure, we expect that direct effects of the smoke, inflammation, and increased matrix degradation contribute to the stress imposed on the epithelium, which leads to the induction of RAET1 expression. Our present results highlight the difficulties of dissecting the cellular and molecular mechanisms of a complex disease, but demonstrate that the development of an experimental model of reduced complexity can help delineate the role of CTLs in COPD pathogenesis.

An important consideration in these studies is that the pathologies are dependent on sustained as opposed to transient expression of NKG2D ligands in the pulmonary microenvironment. Several acute experimental exposures initiate pulmonary NKG2D ligand expression in mice in a transient manner, including pul- 
monary bacterial infection (23) and exposure to pulmonary irritants (e.g., ozone and acrolein; M.T. Borchers, unpublished observation). Similar to in vitro studies with human pulmonary epithelial cells (22), acute exposures lead to maximal induction of NKG2D ligand expression at 24-48 h that rapidly returns to baseline. Under all the above-described conditions, acute expression of NKG2D ligands does not lead to irreversible changes in the pulmonary architecture. However, the present study demonstrated that inducible, sustained expression of NKG2D ligands in mice occurred following chronic exposure to cigarette smoke and that sustained pulmonary expression of NKG2D ligands in the Raet1a $\mathrm{Tg}$ mouse model was sufficient to cause pulmonary emphysema. More importantly, we demonstrated that upregulation of NKG2D ligands in COPD patients was likewise persistent, as evidenced by the lack of association between MICA upregulation and either infection or smoking status. These data also demonstrate the importance of determining whether NKG2D pathway blockade is effective in attenuating experimental emphysema development induced by cigarette smoke.

The immune system can be activated by signals from cells exposed to pathogens, environmental stimuli, or mechanical damage. The presumed function of stress immunosurveillance is to contribute to tissue repair and maintenance by eliminating stressed or damaged cells and to facilitate the restoration of healthy cells $(7,50)$. In the context of COPD, the local pulmonary immune system appears to be chronically responding as if it recognizes a tumor cell or virus-infected cell. Although CTL activation in response to tumors and pathogens is highly beneficial to the host, the CTL response to chemically stressed cells (e.g., cigarette smoking) is ultimately detrimental to the susceptible host as it contributes to the imbalance in tissue injury/repair that is a pathognomonic feature of COPD. Previously, we reported that cultured human airway epithelial cells respond to acute oxidative stress by transiently expressing several known ligands for NKG2D (22). Although the present study did not address the mechanisms of NKG2D ligand induction on pulmonary cells, we presume that it is likely a combination of direct effects of the many toxicants present in cigarette smoke and the indirect effects of products of tissue damage. Along these lines, NKG2D ligand induction has previously been reported in response to toll-like receptor stimulation (51) and DNA damage (10). In this context, NKG2D ligand induction represents a general mechanism of immune cell activation used by the lung under stress.

We provide the first evidence to our knowledge that the NKG2D pathway is associated with COPD, particularly the morphological and/or physiological endpoints of emphysema. We demonstrated that in multiple mouse models of emphysema, RAET1 expression was strongly associated with the development of airspace enlargement. In human COPD patients, bronchial biopsies demonstrated that MICA staining was associated with cigarette smoking and emphysema development. Similarly, MICA expression increased in peripheral lung tissue from a separate COPD patient population. Investigators have hypothesized that COPD represents an autoimmune disease and suggested that aberrant activation of the immune system accounts for the findings that inflammation persists and lung function continues to decline in former smokers $(52,53)$. Several findings support the concept that autoimmune reactions accompany COPD pathogenesis. Oligoclonal expansions of $\mathrm{CD}^{+} \mathrm{T}$ cells in emphysematous lung tissue of patients undergoing thoracic surgery have been reported (54), but these find- ings may reflect the response to current infection or tumor. More recently, we have demonstrated clonal expansions in predominantly $\mathrm{CD}^{+} \mathrm{T}$ cells in a mouse model of COPD devoid of infections or tumors (55). Direct evidence of autoimmunity is provided by the reports that circulating antibodies against elastin fragments correlate with emphysema severity (56) and that autoantibodies against pulmonary epithelial cells are present in COPD patients (57). Our present findings support the hypothesis that persistent NKG2D ligand expression on pulmonary epithelial cells, and the subsequent pathological consequences, is a form of autoimmunity because it reflects a breakdown in self tolerance. The emerging picture is that immunopathogenesis represents an important component of COPD progression.

Presently, it is unknown whether activation of the NKG2D pathway contributes to other chronic pulmonary diseases, or whether other exposures (e.g., passive exposure to cigarette smoke or other inhaled pollutants or viral infections), if any, are also associated with aberrant MICA expression in the lung. However, the potential pathogenic role of current or former active smoking is highlighted in the present study, as MICA was associated with smoking whereas it was not detected in any bronchial sample obtained from the limited number of patients with nonsmoking COPD or in former smokers without COPD. In addition, examination of a limited number of never smoker asthma patients failed to reveal any MICA immunoreactivity in bronchial biopsy material (data not shown). There was no a priori evidence that any immune functions are disease specific. Indistinguishable lymphocyte effector functions are triggered in response to pathogens, cancer, and autoimmune reactions. Therefore, the consequences of NKG2D ligand expression are likely dependent on temporal and spatial expression (airway versus alveoli) and the context of the unique pulmonary immune microenvironment.

In summary, our findings that NKG2D mediated CTL activation after exposure to cigarette smoke, that NKG2D ligand expression caused emphysema in transgenic mice, and that NKG2D ligands were aberrantly expressed in the pulmonary epithelium of both animal models and patients with COPD, which coincided with emphysema development, provide mechanistic insight into COPD pathogenesis. These data provide a more comprehensive picture of COPD and increase our understanding of the effects of current treatments and new therapeutics developed for COPD patients. Moreover, we demonstrated that anti-NKG2D blocking antibody abrogated emphysema development in the animal model, which suggests the NKG2D pathway maybe a molecular target for complementary treatment and/or prevention of emphysema. An increased understanding of how the pulmonary epithelium communicates with the immune system in order to maintain healthy tissue will provide the foundation for future investigations to determine the role of lymphocyte subpopulations in pulmonary diseases in which injury and repair are in disequilibrium.

\section{Methods}

Mice. All procedures were conducted using mice $8-12 \mathrm{wk}$ of age maintained in ventilated microisolator cages housed in an American Association for Accreditation of Laboratory Animal Care-accredited animal facility. Protocols and studies involving animals were conducted in accordance with NIH guidelines and were approved by the Institutional Animal Care and Use Committee of the University of Cincinnati College of Medicine.

Animal exposures. Mice (8-wk-old female BALB/CJ; The Jackson Laboratory) were exposed to filtered air or $150 \mathrm{mg} / \mathrm{m}^{3}$ cigarette smoke from stan- 
dard research cigarettes (2R4F; University of Kentucky Tobacco Research and Development Center) - 4 h per d, $5 \mathrm{~d}$ per wk - for 6 mo using the Teague TE-10Z whole body exposure system (Teague Enterprises). Mice (8-wk-old female C57BL/6J; The Jackson Laboratory) were exposed to filtered air or $2.0 \mathrm{ppm}$ acrolein $-6 \mathrm{~h}$ per $\mathrm{d}, 5 \mathrm{~d}$ per wk - for up to $12 \mathrm{wk}$ as previously described (58) to induce the hallmark features of COPD.

Immunohistochemistry. RAET1 immunohistochemistry was performed on formalin-fixed, paraffin-embedded mouse lung tissue with a goat polyclonal antibody (clone AF1136; R\&D Systems) as previously described (23). Pro-SPC was detected with a rabbit polyclonal antibody (Chemicon). RAET1 and pro-SPC dual labeling was visualized using alkaline phosphate-labeled secondary antibody kits (Vectastain ABC-AP kit; Vector Laboratories) with Vector Red and Vector Blue Alkaline Phosphate Substrate kits (Vector Laboratories) according to manufacturer's recommendations. Activated Casp3 protein was detected with a rabbit polyclonal antibody (R\&D Systems) in 5- $\mu \mathrm{m}$ paraffin sections of mouse lung tissue as previously described (27). RAET $1^{+}$and $\mathrm{Casp}^{+}$cells were quantitated as the number of positive cells per randomly chosen high-power field $(\times 400$ magnification) of 5 fields per section from 3 sections per mouse $(n=5-8$ mice per group).

MICA immunoreactivity was assessed using a mouse anti-human MICA- $\beta_{1}$ monoclonal antibody (clone AMO1; Immatics Biotechnologies) as described in Supplemental Figure 2. Both immunofluorescence and immunoperoxidase techniques were similarly performed on adjacent sections using FITCconjugated and peroxidase-conjugated anti-mouse secondary antibodies (BD Biosciences - Pharmingen). Confocal microscopy was performed using a Leica SP2 confocal scanning laser microscope adapted to an inverted Leica DM IRBE microscope. Immunoreactivity was assessed on peroxidase-stained sections using a single-blind approach by 3 investigators and was expressed as a binomial categorical variable, $\mathrm{MICA}^{-}$or $\mathrm{MICA}^{+}$. $\mathrm{MICA}^{+}$was defined using 2 objective criteria obtained from a computer-assisted image analysis based on epithelial staining: the hue and saturation of the reaction, and the stained area fraction (see Supplemental Figure 2).

Isolation of mouse alveolar epithelial cells and flow cytometry. Primary alveolar epithelial cells were isolated and maintained as previously reported (59). Lungs were perfused with $10 \mathrm{ml}$ of $0.9 \%$ saline through the right ventricle, and $3 \mathrm{ml}$ Dispase (Fisher) was instilled through a cannula in the trachea, followed by $1 \mathrm{ml}$ of $1 \%$ low melt agarose (Promega). After a 2-min incubation of the animal on ice to harden the agarose, the lungs were removed and incubated separately in $1 \mathrm{ml}$ Dispase for $45 \mathrm{~min}$ at room temperature. Lungs were then placed in 60-mm culture dishes containing $7 \mathrm{ml}$ DMEM (Mediatech), $20 \mathrm{mM}$ HEPES (Fisher), $100 \mathrm{U} / \mathrm{ml}$ penicillin-streptomycin (Invitrogen), and $100 \mathrm{U} / \mathrm{ml}$ DNAse I (Sigma-Aldrich). The lungs were gently teased away from the cell suspension, agitated for $10 \mathrm{~min}$, and placed on ice. The cell suspension was filtered successively through $100-\mu \mathrm{m}, 40-\mu \mathrm{m}$, and $20-\mu \mathrm{m}$ nylon gauze and centrifuged for $8 \mathrm{~min}$ at $130 \mathrm{~g}$. After centrifugation, cells were resuspended in complete DMEM (containing $20 \mathrm{mM}$ HEPES, $10 \% \mathrm{FBS}$, and $100 \mathrm{U} / \mathrm{ml}$ penicillin-streptomycin). Cells were then incubated on precoated dishes containing $45 \mu \mathrm{g} / \mathrm{ml}$ anti-mouse CD 45 and $16 \mu \mathrm{g} / \mathrm{ml}$ anti-mouse CD32 for $2 \mathrm{~h}$ in a tissue culture incubator $\left(5 \% \mathrm{CO}_{2}\right.$ at $37^{\circ} \mathrm{C}$ ). Nonadherent cells were panned from the antibody plates, rinsed with complete DMEM, centrifuged, and resuspended in complete DMEM. The cells were then placed in 6-well plates precoated with a mixture of $80 \%$ Matrigel (BD Biosciences) and 20\% complete DMEM. Cell purity was determined by light microscopy. Cells were maintained in complete DMEM.

CSE and treatment. CSE was generated by bubbling smoke from 1 standard reference cigarette into $10 \mathrm{ml}$ PBS through a 50-ml fritted impinger at a flow rate of $350 \mathrm{ml} / \mathrm{min}$. The resulting extract was passed through a $0.22-\mathrm{mm}$ filter and was considered $100 \%$ CSE. The CSE was adjusted to $\mathrm{pH} 7.4$ by the addition of $\mathrm{NaOH}$ before addition to the epithelial cell cultures. CSE treatment was performed in 6-well plates, and experiments were performed using cells at approximately $80 \%$ confluence. Briefly, cells were replenished with fresh media, allowed to equilibrate for $2 \mathrm{~h}\left(5 \% \mathrm{CO}_{2}\right.$ at $\left.37^{\circ} \mathrm{C}\right)$, and exposed to CSE or PBS for $24 \mathrm{~h}$. Cells were released from the Matrigel with Matrisperse (BD Biosciences) nonenzymatic recovery solution according to the manufacturer's instructions in order to ensure minimal distress to the cell surface ligands. RAET1 expression on the surface of epithelial cells was determined by staining with the anti-RAET1 $\alpha$-RAET1 $\varepsilon$ monoclonal antibody (clone 186107; R\&D Systems). Flow cytometry was performed on a FACScan cytofluorometer (BD), and data acquisition and analysis was performed using CellQuest Pro software (version 5.2; BD).

Preparation of mouse lymphocytes and cytotoxicity assays. Lymphocytes were isolated and purified from mouse spleen using a magnetic cell separation system according to the manufacturer's protocol (Miltenyi Biotech). The protocol uses a negative selection strategy to magnetically retain antibodybound granulocytes. The effluent from this protocol yields untouched, enriched lymphocytes. A recovery of approximately $40 \%$ lymphocytes per spleen was typical. Approximately $20 \%$ of splenic lymphocytes express NKG2D upon isolation, and do so for up to $12 \mathrm{~d}$ when maintained in RPMI- 1640 containing 1,000 U/ml recombinant human IL-2. All coculture studies were conducted with freshly isolated cells in RPMI- 1640 containing $1,000 \mathrm{U} / \mathrm{ml}$ recombinant human IL-2 and mouse alveolar epithelial cells treated with $3 \%$ CSE or PBS for 24 h. Cytotoxicity assays were performed using the CytoTox 96 Non-Radioactive Cytotoxicity Assay (Promega) according to the manufacturer's instructions.

Raet1 Tg mice. Ccsp-rtta transgenic mice, on the FVBN background, were previously generated (24), and DOX-inducible Raet1a-expressing mice, on the FVBN background, were generated at the University of Cincinnati using Raet1a cDNA obtained by PCR cloning as described in Supplemental Figure 1 and in previous publications $(24,25)$. DOX was administered in the diet (TD.01306 rodent diet, 2,018 diet and $625 \mathrm{mg}$ DOX; Harlan Teklad) beginning at $8-10 \mathrm{wk}$ of age.

Morphometric analysis and pulmonary mechanics. The average intra-alveolar distance was calculated as the mean linear intercept on H\&E-stained sections of inflation-fixed $\left(20 \mathrm{~cm} \mathrm{H}_{2} \mathrm{O}\right)$ mouse lungs, as previously detailed (60). Total respiratory system mechanics were assessed in mice using the forced oscillation technique (FlexiVent; Scireq) according to the method of Gomes (61).

Anti-NKG2D administration. NKG2D receptor function was blocked by i.p. administration of the rat anti-mouse NKG2D monoclonal antibody CX5 (eBioscience) under conditions identical to those previously reported (23).

In vivo lymphocyte depletion. Lymphocyte populations were depleted by repeated i.p. administration of antibodies (100-200 $\mu \mathrm{g} /$ mouse, every $4 \mathrm{~d}$ beginning $8 \mathrm{~d}$ prior to DOX administration) specific for NK cells (anti-asialo GM1; Wako Chemicals USA), $\alpha \beta$ T cells (clone H57-97), $\gamma \delta$ T cells (clone UC7-13D5), CD4+ cells (clone GK1.5), and CD8 ${ }^{+}$cells (clone 2.43). All TCR antibodies were kindly provided by G. Deepe (University of Cincinnati). Lymphocyte depletion was greater than $90 \%$ in all experiments, as confirmed by analyzing peripheral blood cells using the detection antibodies against the following cell types: NK cells (anti-NKp46, clone 29A1.4; eBioscience), $\alpha \beta$ T cells (clone 145-2C11; BD Biosciences - Pharmingen), $\gamma \delta$ T cells (clone GL3; BD Biosciences - Pharmingen), CD4 cells (clone LT34; BD Biosciences - Pharmingen), and CD8 cells (clone 53-67; BD Biosciences - Pharmingen).

Caspase bioassay. Whole lung homogenates were prepared in PBS, and commercially available kits were used to estimate the activity of Casp3/7 according to manufacturer's instructions (Apo-ONE Homogenous Caspase-3/7 Assay; Promega).

Quantitative real-time PCR. Total RNA was isolated from mouse lung with TRIzol Transcription Kit (Applied Biosystems). For each gene examined, quantitative RT-PCR was performed on an ABI 7300 System using pre- 
validated TaqMan Gene Expression Assays Reagent (Invitrogen) and subsequently converted into cDNA using the High Capacity cDNA Reverse according to the manufacturer's standard protocols (Applied Biosystems). Gene expression was normalized to the Hprt1 endogenous control gene, and relative quantitation of gene expression was calculated using the comparative Ct method $\left(2^{-\Delta \Delta \mathrm{Ct}}\right)$.

$B A L$ and cell enumeration. After exposure, mice were anesthetized $(50 \mathrm{mg} / \mathrm{kg}$ of pentobarbital sodium i.p.) and exsanguinated by severing the posterior abdominal aorta. The lungs were then lavaged 2 times with $1 \mathrm{ml}$ HBSS. Individual BAL returns were pooled and centrifuged at $300 \mathrm{~g}$ for $10 \mathrm{~min}$. The supernatant was removed and stored at $70^{\circ} \mathrm{C}$. The cell pellet was reconstituted in $1 \mathrm{ml} \mathrm{HBSS}$ containing $2 \%$ FBS. Total cell counts were determined with a hemocytometer. Differential cell counts ( $>300$ cells) were performed on Diff-Quik-stained (Baxter Diagnostics) cytospin slides (Cytospin3; Shandon Scientific).

Pulmonary lymphocyte characterization. Single cell suspensions from perfused, digested lungs were layered onto a single-step Percoll gradient (60\% Percoll, $\rho=1.084 ; 1 \times$ HBSS; and 15 mM HEPES, $\mathrm{pH} 7.4$ ) and centrifuged at $2,000 \mathrm{~g}$ for $45 \mathrm{~min}$ at $4^{\circ} \mathrm{C}$. The buffy coat containing mononuclear cells was removed and washed twice in PBS containing $2 \%$ FCS. The cell pellet was then subject to red blood cell lysis, washed, and resuspended in PBS containing $2 \%$ FCS. Cells were labeled with antibodies against CD3 (clone 145-2C11; BD Biosciences - Pharmingen), TCR 8 (clone GL3; BD Biosciences - Pharmingen), CD4 (clone GK1.5; BD Biosciences Pharmingen), CD8 (clone 53-6.7; BD Biosciences - Pharmingen), NK1.1 (clone PK136; BD Biosciences), and NKG2D (clone CX5; eBiosciences). Cells were analyzed by flow cytometry using a FACScan cytofluorometer (BD). Data acquisition and analysis were performed using CellQuest Pro software (version $5.2 ; \mathrm{BD}$ ).

Zymogram. Mice were anesthetized $(50 \mathrm{mg} / \mathrm{kg}$ of pentobarbital sodium i.p.) and exsanguinated by severing the posterior abdominal aorta. Lungs were removed, immersed in liquid nitrogen, and homogenized in HBSS. Gelatin zymography was performed using whole lung homogenates. Briefly, $60 \mu \mathrm{g}$ lung protein in $2 \times$ Tris-Glycine gel loading buffer was electrophoresed at $125 \mathrm{~V}$ for $60 \mathrm{~min}$ in a $10 \%$ Tris-Glycine gel containing $0.1 \%$ gelatin (Invitrogen). Gels were washed twice in zymogram renaturing solution, preincubated for $30 \mathrm{~min}$ at $37^{\circ} \mathrm{C}$ in zymogram developing solution, and incubated in zymogram developing solution (Invitrogen). Gels were stained with $0.5 \%$ Coomassie blue (Sigma-Aldrich) in $40 \%$ methanol and $10 \%$ acetic acid $\left(1 \mathrm{~h}, 22^{\circ} \mathrm{C}\right)$ and destained in $40 \%$ methanol and $10 \%$ acetic acid $\left(1 \mathrm{~h}, 22^{\circ} \mathrm{C}\right)$, with 2 changes of destaining solution to visualize digested bands in the gelatin matrix. A parallel SDS-PAGE gel was loaded with $60 \mu \mathrm{g}$ protein and stained with Coomassie blue as a loading control. Gels were photographed using a FOTO/Analyst Investigator System digital camera (Fotodyne).

Human ethics and study design. Bronchial biopsies and surgical specimens were collected from 2 separate patient study groups. The Research Committee of Human Investigation at IMIM approved the study for endoscopic biopsy collection from adult patients admitted to the Bronchoscopy Facility for diagnostic purposes. Written informed consent was obtained from each participant. The Institutional Review Board of the University of Cincinnati College of Medicine approved protocols to obtain surgical specimens from patients undergoing thoracic surgery procedures for benign and malignant disease.

Patient identification and case enrollment. For both study groups, COPD diagnosis was made according to Global Initiative for Obstructive Lung Disease criteria (1). All patients undergoing endoscopic bronchial biopsy were clinically stable for more than $2 \mathrm{mo}$. Some patients received regular treatment with inhaled bronchodilators $(n=21)$ and/or inhaled steroids $(n=7)$. Patients were excluded for reasons of COPD exacerbation in the last 3 mo, clinical suspicion of bronchial asthma, treatment with systemic steroids within the last 2 mo, or tumor observed in the trachea or main bronchi during bronchoscopy. Smoking status data was collected via a questionnaire. Exhaled $\mathrm{CO}$ was measured to confirm smoking cessation or continued smoking.

Pulmonary function. For patients undergoing endoscopic bronchial biopsy, pulmonary function was assessed by forced spirometry (Datospir 900; SIBEL). Static lung volume determination, airway resistance, and TLCo were determined using plethysmography and single breath analysis (Masterlab; Jaeger). Reference values used were those for the Mediterranean population (62).

For patients undergoing thoracoscopic procedures at the University of Cincinnati, pulmonary function was tested using the Vmax Encore (Viasys Healthcare) according to American Thoracic Society guidelines (63). Reference values for this population were determined according to Morris (64). COPD was diagnosed according to the Global Initiative for Obstructive Lung Disease (1). Clinical patient characteristics from the 2 institutions were similar in pack years, pulmonary function parameters, and tumor incidence. See Table 1 and Supplemental Tables 1-3 for complete demographic and clinical characteristics of both patient groups.

CT of the lungs. CT of the lungs was available in 76 (93\%) of the selected study subjects. All CT scans were taken in the supine position with 1.25 and $7 \mathrm{~mm}$ collimation, scanning time of $0.75 \mathrm{~s}, 120 \mathrm{kV}$, and $90 \mathrm{mAs}$ (SOMATOM Sensation 4; Siemens). Images were reconstructed using high (B70) and low (B40) spatial frequency resolution algorithms for all cases. The machines were calibrated with standard protocols every 6 mo using the manufacturers' standard phantom and yearly, according to the national regulatory guidelines. Scans were obtained at full inspiration, and no i.v. contrast was used. Scans were independently examined for the presence of emphysema by radiologists blinded to the subjects' clinical history. The radiological diagnosis of emphysema was made if centrilobular low-density areas or panlobular or paraseptal emphysematous changes were present, and subjects were graded as having no evidence of emphysema, changes suggestive of emphysema, or definite emphysema. In cases of discordance, the images were viewed together and a consensus decision reached. Only subjects with definite emphysema were included as having macroscopic disease in subsequent analyses (42).

Bronchoscopy, bronchial biopsies, and surgical specimen collection. Endobronchial biopsy specimens were obtained by direct visualization using a flexible videobronchoscope (BF-200; Olympus) and bronchial biopsy forceps (FB 21-C; Olympus) from macroscopically normal areas of the third order carina as previously described (65). Biopsies were preserved in formalin and fixed in paraffin. Surgical specimens were obtained from patients who underwent pulmonary resections for benign and malignant processes. Surgical specimens were obtained from lung tissue distant from the tumor site and were cut by a certified pathologist within the Anatomic Pathology Department, University of Cincinnati Hospital. Portions of the surgical specimens were snap frozen in liquid nitrogen and subsequently stored at $-80^{\circ} \mathrm{C}$ until protein extraction. In some patients, portions were immediately placed in cell culture media and enzymatically digested as described below.

Immunoblots. Protein isolation and immunoblot analyses were performed as previously described (22). Membranes were incubated overnight with anti-MICA (catalog no. AF1300; R\&D Systems) or anti-granzyme B (clone 216315; R\&D Systems), then incubated with IgG-HRP-conjugated secondary antibody and detected by chemiluminescence (ECL Reagents; Amersham). Membranes were stripped and reprobed with anti-GAPDH or anti- $\beta$-actin antibodies (Santa Cruz Biotechnology Inc.). Individual MICA and $\beta$-actin bands were quantitated by scanning densitometry using ImageQuant software (version 5.2; Molecular Dynamics).

Human lung cell isolation and flow cytometry. Freshly isolated lung tissue $(\sim 1.0 \mathrm{~g})$ obtained from patients undergoing surgical resections was diced 
into pieces of less than $500 \mu \mathrm{l}$ in $4 \mathrm{ml}$ HBSS containing $175 \mathrm{U} / \mathrm{ml}$ collagenase, $0.2 \mathrm{U} / \mathrm{ml}$ pancreatic elastase, $35 \mathrm{U} / \mathrm{ml}$ hyaluronidase, $20 \mathrm{KU} / \mathrm{ml}$ DNAse (Sigma-Aldrich), 10\% FCS, $100 \mathrm{U} / \mathrm{ml}$ penicillin, and $100 \mu \mathrm{g} / \mathrm{ml}$ streptomycin (CellGro) and incubated for $30 \mathrm{~min}$ at $37^{\circ} \mathrm{C}$ on an orbital shaker. Digested tissue was sheared through a 20 -gauge needle and passed through $40-\mu \mathrm{m}$ filters. Leukocytes were recovered by layering over a $30 \%$ Percoll solution and centrifuging at $400 \mathrm{~g}$ for $40 \mathrm{~min}$. Identification of $\mathrm{CD}^{+}$(anti-human CD3, clone SK7, PerCP-C5.5 conjugated; BD Biosciences), $\mathrm{CD}^{+}$(anti-human CD4, clone RPA-T4, FITC conjugated; BD Biosciences), $\mathrm{CD}^{+}$(anti-human CD8, clone HIT8a, PE conjugated; BD Biosciences), NK (anti-human CD56, clone B159, APC conjugated; BD Biosciences), and NKG2D (anti-human NKG2D, clone 1D11, APC conjugated; BD Biosciences) cell populations was determined by flow cytometry using a FACSCalibur cytofluorometer (BD). Data acquisition and analysis was performed using CellQuest Pro software (version 5.2; BD).

Statistics. Animal data were analyzed for normality using SigmaStat software (version 3.5; Systat Software). Significant differences among groups were identified by ANOVA, and individual comparisons between groups were confirmed by a post-hoc Tukey test, with differences between means considered significant at $P<0.05$. All data presented are mean $\pm \mathrm{SD}$. The relationship between RAET1 and alveolar diameter in mouse models was assessed by an exponential rise, 2 parameter nonlinear regression analysis $\left(y=a\left[1-e^{-b x}\right]\right)$ performed using SigmaStat software.

Clinical characteristics are expressed as mean and SD or as a percentage. MICA frequency comparison between different groups was performed by $\chi^{2}$ test. Mean values of pulmonary function variables were compared using 2-tailed Student's $t$ test between $\mathrm{MICA}^{+}$and $\mathrm{MICA}^{-}$patients. Risk estimates were assessed by logistic regression. A $P$ value of less than 0.05 was considered significant. Clinical statistics were performed using Stata (release 8.0; StataCorp).

1. Pauwels, R.A., Buist, A.S., Calverley, P.M., Jenkins, C.R., and Hurd, S.S. 2001. Global strategy for the diagnosis, management, and prevention of chronic obstructive pulmonary disease. NHLBI/WHO Global Initiative for Chronic Obstructive Lung Disease (GOLD) Workshop summary. Am. J. Respir. Crit. Care Med. 163:1256-1276.

2. Murray, C.J., and Lopez, A.D. 1996. Evidence-based health policy - lessons from the Global Burden of Disease Study. Science. 274:740-743.

3. Barnes, P.J., Shapiro, S.D., and Pauwels, R.A. 2003. Chronic obstructive pulmonary disease: molecular and cellular mechanisms. Eur. Respir. J. 22:672-688.

4. Grumelli, S., et al. 2004. An immune basis for lung parenchymal destruction in chronic obstructive pulmonary disease and emphysema. PLoS Med. 1:e8.

5. Cosio, M.G. 2004. Autoimmunity, T-cells and STAT-4 in the pathogenesis of chronic obstructive pulmonary disease. Eur. Respir. J. 24:3-5.

6. Taraseviciene-Stewart, L., and Voelkel, N.F. 2008 Molecular pathogenesis of emphysema. J. Clin. Invest. 118:394-402.

7. Gleimer, M., and Parham, P. 2003. Stress management: MHC class I and class I-like molecules as reporters of cellular stress. Immunity. 19:469-477.

8. Raulet, D.H. 2003. Roles of the NKG2D immunoreceptor and its ligands. Nat. Rev. Immunol. 3:781-790.

9. Ogasawara, K., et al. 2003. Impairment of NK cell function by NKG2D modulation in NOD mice. Immunity. 18:41-51.

10. Gasser, S., Orsulic, S., Brown, E.J., and Raulet, D.H. 2005. The DNA damage pathway regulates innate immune system ligands of the NKG2D receptor. Nature. 436:1186-1190.

11. Groh, V., et al. 1996. Cell stress-regulated human major histocompatibility complex class I gene expressed in gastrointestinal epithelium. Proc. Natl. Acad. Sci. U. S. A. 93:12445-12450.

\section{Acknowledgments}

The authors gratefully thank Thomas Spies, Veronika Groh (Fred Hutchinson Cancer Research Center, Seattle, Washington, USA), Angel Gayete (CRC Mar, Hospital del Mar, Barcelona, Spain), and Josep M. Antó (Respiratory and Environmental Research Unit, Municipal Institute of Medical Research, Barcelona, Spain), for helpful analyses and discussions. The University of Cincinnati Transgenic Core Facility, John Leikauf, Michael Graves, Alejandro Canelos, Jay Asplan, and Patricio Esquivel provided excellent technical assistance. The authors acknowledge X. SanJuan (Pompeu Fabra University, Barcelona, Spain), B. Abeijón (Hospital del Mar, Barcelona, Spain), and B. Casado (Muscle and Respiratory Research Unit, IMIM) for assistance with immunohistochemistry and confocal microscopy. This work was supported by Red RESPIRA (RTIC-C03/11, Fondo de Investigación Sanitaria, Instituto de Salud Carlos III, Spain), ISCIII BA06/90061, ARMAR, ERESMUS in COPD (BMTH4-CT98-3406, E.U.), SOCAP 2004, Becario SEPAR 2005, CIBER de Enfermedades Respiratorias, FIS-PI-05-2438 (M. Orozco-Levi), the Health Effects Institute (M.T. Borchers), University of Cincinnati Center for Environmental Genetics grant P30-ES06096-02 (M.T. Borchers), and NIH grant R01 ES015036 (M.T. Borchers).

Received for publication April 9, 2008, and accepted in revised form December 22, 2008.

Address correspondence to: Michael T. Borchers, Department of Environmental Health, Division of Environmental Genetics, University of Cincinnati College of Medicine, Cincinnati, Ohio 452670056, USA. Phone: (513) 558-6424; Fax: (513) 558-0925; E-mail: michael.borchers@uc.edu.
12. Groh, V., et al. 1999. Broad tumor-associated expression and recognition by tumor-derived gamma delta T cells of MICA and MICB. Proc. Natl. Acad. Sci. U. S. A. 96:6879-6884.

13. Jinushi, M., et al. 2003. Expression and role of MICA and MICB in human hepatocellular carcinomas and their regulation by retinoic acid. Int. J. Cancer. 104:354-361.

14. Tieng, V., et al. 2002. Binding of Escherichia coli adhesin AfaE to CD55 triggers cell-surface expression of the MHC class I-related molecule MICA. Proc. Natl. Acad. Sci. U. S. A. 99:2977-2982.

15. Bauer, S., et al. 1999. Activation of NK cells and $\mathrm{T}$ cells by NKG2D, a receptor for stress-inducible MICA. Science. 285:727-729.

16. Cosman, D., et al. 2001. ULBPs, novel MHC class Irelated molecules, bind to CMV glycoprotein UL16 and stimulate NK cytotoxicity through the NKG2D receptor. Immunity. 14:123-133.

17. Jan Chalupny, N., et al. 2003. ULBP4 is a novel ligand for human NKG2D. Biochem. Biophys. Res. Commun. 305:129-135.

18. Bacon, L., et al. 2004. Two human ULBP/RAET1 molecules with transmembrane regions are ligands for NKG2D. J. Immunol. 173:1078-1084.

19. Cerwenka, A., et al. 2000. Retinoic acid early inducible genes define a ligand family for the activating NKG2D receptor in mice. Immunity. 12:721-727.

20. Diefenbach, A., et al. 2000. Ligands for the murine NKG2D receptor: expression by tumor cells and activation of NK cells and macrophages. Nat. Immunol. 1:119-126.

21. Carayannopoulos, L.N., Naidenko, O.V., Fremont, D.H., and Yokoyama, W.M. 2002. Cutting edge: murine UL16-binding protein-like transcript 1: a newly described transcript encoding a highaffinity ligand for murine NKG2D. J. Immunol. 169:4079-4083.
22. Borchers, M.T., Harris, N.L., Wesselkamper, S.C., Vitucci, M., and Cosman, D. 2006. NKG2D ligands are expressed on stressed human airway epithelial cells. Am. J. Physiol. Lung Cell Mol. Physiol. 291:L222-L231.

23. Borchers, M.T., et al. 2006. The NKG2D-activating receptor mediates pulmonary clearance of Pseudomonas aeruginosa. Infect. Immun. 74:2578-2586.

24. Tichelaar, J.W., Lu, W., and Whitsett, J.A. 2000. Conditional expression of fibroblast growth factor7 in the developing and mature lung. J. Biol. Chem. 275:11858-11864.

25. Wesselkamper, S.C., et al. 2008. NKG2D is critical for NK cell activation in host defense against pseudomonas aeruginosa respiratory infection. J. Immunol. 181:5481-5489.

26. Hautamaki, R.D., Kobayashi, D.K., Senior, R.M., and Shapiro, S.D. 1997. Requirement for macrophage elastase for cigarette smoke-induced emphysema in mice. Science. 277:2002-2004.

27. Borchers, M.T., et al. 2007. CD8+ T cells contribute to macrophage accumulation and airspace enlargement following repeated irritant exposure. Exp. Mol. Pathol. 83:301-310.

28. Hogg, J.C., et al. 2004. The nature of small-airway obstruction in chronic obstructive pulmonary disease. N. Engl. J. Med. 350:2645-2653.

29. Vernooy, J.H., et al. 2007. Increased granzyme A expression in type II pneumocytes of patients with severe chronic obstructive pulmonary disease. Am. J. Respir. Crit. Care Med. 175:464-472.

30. Hogg, J.C. 2004. Pathophysiology of airflow limitation in chronic obstructive pulmonary disease. Lancet. 364:709-721.

31. Finkelstein, R., Fraser, R.S., Ghezzo, H., and Cosio, M.G. 1995. Alveolar inflammation and its relation to emphysema in smokers. Am. J. Respir. Crit. Care Med. 152:1666-1672. 
32. O'Shaughnessy, T.C., Ansari, T.W., Barnes, N.C., and Jeffery, P.K. 1997. Inflammation in bronchial biopsies of subjects with chronic bronchitis: inverse relationship of CD8+ T lymphocytes with FEV1. Am. J. Respir. Crit. Care Med. 155:852-857.

33. Saetta, M., et al. 1999. CD8+ve cells in the lungs of smokers with chronic obstructive pulmonary disease. Am. J. Respir. Crit. Care Med. 160:711-717.

34. Majo, J., Ghezzo, H., and Cosio, M.G. 2001. Lymphocyte population and apoptosis in the lungs of smokers and their relation to emphysema. Eur. Respir. J. 17:946-953.

35. Upshaw, J.L., and Leibson, P.J. 2006. NKG2D-mediated activation of cytotoxic lymphocytes: unique signaling pathways and distinct functional outcomes. Semin. Immunol. 18:167-175.

36. Dann, S.M., et al. 2005. Interleukin-15 activates human natural killer cells to clear the intestinal protozoan cryptosporidium. J. Infect. Dis. 192:1294-1302.

37. Takaki, R., et al. 2005. IL-21 enhances tumor rejection through a NKG2D-dependent mechanism. J. Immunol. 175:2167-2173.

38. Song, H., et al. 2006. IL-2/IL-18 prevent the downmodulation of NKG2D by TGF-beta in NK cells via the c-Jun $\mathrm{N}$-terminal kinase (JNK) pathway. Cell Immunol. 242:39-45.

39. Markiewicz, M.A., et al. 2005. Costimulation through NKG2D enhances murine CD8+ CTL function: similarities and differences between NKG2D and CD28 costimulation. J. Immunol. 175:2825-2833.

40. Collins, R.W., Stephens, H.A., Clare, M.A., and Vaughan, R.W. 2002. High resolution molecular phototyping of MICA and MICB alleles using sequence specific primers. Hum. Immunol. 63:783-794.

41. Omori, H., Fujimoto, K., and Katoh, T. 2008. Computed-tomography findings of emphysema: correlation with spirometric values. Curr. Opin. Pulm. Med. 14:110-114.

42. Marsh, S., et al. 2007. Utility of lung density measurements in the diagnosis of emphysema. Respir.
Med. 101:1512-1520.

43. Hayakawa, Y., et al. 2002. Cutting edge: tumor rejection mediated by NKG2D receptor-ligand interaction is dependent upon perforin. J. Immunol. 169:5377-5381.

44. Smyth, M.J., et al. 2004. NKG2D recognition and perforin effector function mediate effective cytokine immunotherapy of cancer. J. Exp. Med. 200:1325-1335.

45. Chrysofakis, G., et al. 2004. Perforin expression and cytotoxic activity of sputum CD8+ lymphocytes in patients with COPD. Chest. 125:71-76.

46. Maeno, T., et al. 2007. CD8+ T Cells are required for inflammation and destruction in cigarette smoke-induced emphysema in mice. J. Immunol. 178:8090-8096.

47. Groh, V., et al. 2001. Costimulation of CD8alphabeta $T$ cells by NKG2D via engagement by MIC induced on virus-infected cells. Nat. Immunol. 2:255-260.

48. Sutherland, C.L., et al. 2002. UL16-binding proteins, novel MHC class I-related proteins, bind to NKG2D and activate multiple signaling pathways in primary NK cells. J. Immunol. 168:671-679.

49. Kubin, M., et al. 2001. ULBP1, 2, 3: novel MHC class I-related molecules that bind to human cytomegalovirus glycoprotein UL16, activate NK cells. Eur. J. Immunol. 31:1428-1437.

50. Janeway, C.A., Jr., Jones, B., and Hayday, A. 1988. Specificity and function of $\mathrm{T}$ cells bearing gamma delta receptors. Immunol. Today. 9:73-76.

51. Hamerman, J.A., Ogasawara, K., and Lanier, L.L. 2004. Cutting edge: toll-like receptor signaling in macrophages induces ligands for the NKG2D receptor. J. Immunol. 172:2001-2005.

52. Agusti, A., MacNee, W., Donaldson, K., and Cosio, M. 2003. Hypothesis: does COPD have an autoimmune component? Thorax. 58:832-834.

53. Barnes, P.J., and Cosio, M.G. 2004. Characterization of T lymphocytes in chronic obstructive pulmonary disease. PLoS Med. 1:e20.
54. Sullivan, A.K., et al. 2005. Oligoclonal CD4+ T cells in the lungs of patients with severe emphysema. Am. J. Respir. Crit. Care Med. 172:590-596.

55. Motz, G.T., et al. 2008. Persistence of lung CD8 T cell oligoclonal expansions upon smoking cessation in a mouse model of cigarette smoke-induced emphysema. J. Immunol. 181:8036-8043.

56. Lee, S.H., et al. 2007. Antielastin autoimmunity in tobacco smoking-induced emphysema. Nat. Med. 13:567-569.

57. Feghali-Bostwick, C.A., et al. 2008. Autoantibodies in patients with chronic obstructive pulmonary disease. Am. J. Respir. Crit. Care Med. 177:156-163.

58. Borchers, M.T., et al. 2007. CD8(+) T cells contribute to macrophage accumulation and airspace enlargement following repeated irritant exposure. Exp. Mol. Pathol. 83:301-310.

59. Rice, W.R., et al. 2002. Maintenance of the mouse type II cell phenotype in vitro. Am. J. Physiol. Lung Cell Mol. Physiol. 283:L256-L264.

60. Lyerla, T.A., et al. 2003. Aberrant lung structure, composition, and function in a murine model of Hermansky-Pudlak syndrome. Am. J. Physiol. Lung Cell Mol. Physiol. 285:L643-L653.

61. Gomes, R.F., Shardonofsky, F., Eidelman, D.H., and Bates, J.H. 2001. Respiratory mechanics and lung development in the rat from early age to adulthood. J. Appl. Physiol. 90:1631-1638.

62. Roca, J., et al. 1998. References values for forced spirometry. Group of the European Community Respiratory Health Survey. Eur. Respir. J. 11:1354-1362.

63. Pellegrino, R., et al. 2005. Interpretative strategies for lung function tests. Eur. Respir. J. 26:948-968.

64. Morris, J.F., Koski, A., and Johnson, L.C. 1971. Spirometric standards for healthy nonsmoking adults. Am. Rev. Respir. Dis. 103:57-67.

65. Lopez-Ferrer, A., et al. 2001. Mucins as differentiation markers in bronchial epithelium. Squamous cell carcinoma and adenocarcinoma display similar expression patterns. Am. J. Respir. Cell Mol. Biol. 24:22-29. 